\title{
Subseasonal prediction of springtime Pacific-North American transport using upper-level wind forecasts
}

\author{
John R. Albers ${ }^{1,2}$, Amy H. Butler ${ }^{3}$, Melissa L. Breeden ${ }^{3}$, Andrew O. Langford ${ }^{3}$, and George N. Kiladis ${ }^{2}$ \\ ${ }^{1}$ Cooperative Institute for Research in the Environmental Sciences, University of Colorado Boulder, \\ Boulder, Colorado 80305, USA \\ ${ }^{2}$ NOAA Physical Sciences Laboratory, Boulder, Colorado 80305, USA \\ ${ }^{3}$ NOAA Chemical Sciences Laboratory, Boulder, Colorado 80305, USA
}

Correspondence: John R. Albers (john.albers@noaa.gov)

Received: 2 December 2020 - Discussion started: 16 December 2020

Revised: 18 February 2021 - Accepted: 15 March 2021 - Published: 12 May 2021

\begin{abstract}
Forecasts of Pacific jet variability are used to predict stratosphere-to-troposphere transport (STT) and tropical-to-extratropical moisture export (TME) during boreal spring over the Pacific-North American region. A retrospective analysis first documents the regionality of STT and TME for different Pacific jet patterns. Using these results as a guide, Pacific jet hindcasts, based on zonal-wind forecasts from the European Centre for Medium-Range Weather Forecasting Integrated Forecasting System, are utilized to test whether STT and TME over specific geographic regions may be predictable for subseasonal forecast leads (36 weeks ahead of time). Large anomalies in STT to the midtroposphere over the North Pacific, TME to the west coast of the United States, and TME over Japan are found to have the best potential for subseasonal predictability using upperlevel wind forecasts. STT to the planetary boundary layer over the intermountain west of the United States is also potentially predictable for subseasonal leads but likely only in the context of shifts in the probability of extreme events. While STT and TME forecasts match verifications quite well in terms of spatial structure and anomaly sign, the number of anomalous transport days is underestimated compared to observations. The underestimation of the number of anomalous transport days exhibits a strong seasonal cycle, which becomes steadily worse as spring progresses into summer.
\end{abstract}

\section{Introduction}

Mass transport is important to many aspects of Pacific-North American climate, including the following: stratosphere-totroposphere transport (STT) of ozone to the planetary boundary layer, which has negative impacts on human health (Fiore et al., 2003; U.S. EPA, 2006; Langford et al., 2009; Lefohn et al., 2011); STT to the free troposphere, which is needed to estimate the North American background distribution of ozone (Fiore et al., 2014; Cooper et al., 2015; Young et al., 2018); and water vapor transport, which contributes to precipitation variability (Ralph and Dettinger, 2011; Mahoney et al., 2016; Guan and Waliser, 2015; Gershunov et al., 2017). Because of these impacts, identifying time periods when transport forecasts might be skillful on subseasonal timescales (forecasts 3-6 weeks into the future) is recognized as having high societal value (e.g., Lin et al., 2015; Baggett et al., 2017, and references therein).

Skillful subseasonal transport forecasts hinge, in large part, on the skillful prediction of atmospheric teleconnections (Baggett et al., 2017; DeFlorio et al., 2019). Initial studies of subseasonal teleconnection variability suggested that enhanced predictability might occur during spring when strong El Niño-Southern Oscillation (ENSO) conditions are present (Barnston, 1994; Branković and Palmer, 1997). However, more recent studies suggest that, overall, teleconnections (Wang and Robertson, 2019) and transport (DeFlorio et al., 2019) on subseasonal timescales tend to be most predictable during winter. Indeed, one reason to expect predictability to be lower in spring is that Pacific teleconnec- 
tion patterns become increasingly sensitive to the location and scale of tropical forcing as the Pacific jet undergoes its seasonal transition (Newman and Sardeshmukh, 1998; Barsugli and Sardeshmukh, 2002; discussed in more detail below).

Still, even if teleconnections and transport are more predictable during winter on average, skillfully predicting the atmospheric circulation during spring is important in the context of both STT and water vapor transport. For example, STT of ozone that affects surface air quality occurs primarily during spring (e.g., Lefohn et al., 2011; Langford et al., 2009, 2012; Olsen et al., 2013; Škerlak et al., 2014; Lin et al., 2015). Likewise water vapor transport during spring is also important for many regions of the Pacific basin and North America (e.g., Cayan and Roads, 1984; Lee et al., 2014; Swain et al., 2016; Mundhenk et al., 2016). Thus, here we seek to explore the circumstances whereby skillful transport predictions might be possible during the important, yet potentially less predictable, spring season.

Stratosphere-to-troposphere transport and water vapor transport occur via distinct physical pathways. In midlatitudes, STT occurs mainly via two mechanisms: stratospheric potential vorticity (PV) intrusions, which include tropopause folds, PV streamers, and PV cutoffs (Reed and Danielson, 1958; Hoerling et al., 1993; Langford and Reid, 1998; Shapiro, 1980; Sprenger et al., 2007; Škerlak et al., 2015), and transverse circulations in jet exit regions (Langford et al., 1998; Langford, 1999). Intense water vapor transport events also arise via several distinct, though interrelated, physical processes, including so-called "atmospheric rivers", warm conveyor belts, and tropical moisture exports (Zhu and Newell, 1998; Stohl and James, 2005; Knippertz and Martin, 2007; Knippertz and Wernli, 2010; Newman et al., 2012; Madonna et al., 2014; Pfahl et al., 2014; Knippertz et al., 2013; Ralph et al., 2018; Sodemann et al., 2020). In this study, we focus on spring season STT that extends downwards to the mid-troposphere and planetary boundary layer (PBL) and long-range tropical-to-extratropical water vapor transports, hereafter referred to as tropical moisture export (TME; see Knippertz et al., 2013, for a detailed discussion of TME).

STT and TME have very different seasonal cycles in terms of timing and geography, which is readily observed in monthly mean climatologies (Fig. 1; see Sect. 2 for a detailed description of STT and TME, which are both taken from the database of Sprenger et al., 2017). Over western North America, STT of mass (and ozone) that reaches the PBL peaks in spring (Fig. 1, left column; see also, Škerlak et al., 2014; Albers et al., 2018, and references therein). Despite the strong storm track located over the North Pacific, deep STT into the PBL is limited over the ocean due to a shallow marine boundary layer. In contrast, STT of mass extending downwards into the middle troposphere $(500 \mathrm{hPa})$ peaks during January and February and then slowly decreases thereafter (Fig. 1, middle column). TME also undergoes a seemingly smooth transi- tion during winter and spring, with an initial peak extending from Hawaii to the western United States during February, followed by a slow recession of transport westward, whereby a secondary peak occurs near Japan during May (Fig. 1, third column; see also Knippertz and Wernli, 2010; Mundhenk et al., 2016; Gershunov et al., 2017). The different regional and temporal characteristics of the STT and TME seasonal cycles shown in Fig. 1 are in part a reflection of the different physical processes that govern them, as outlined above. However, at least a portion of STT and TME seasonality and variability are linked by one important commonality: they are both directly modulated by large-scale Rossby waves (e.g., Ryoo et al., 2013; Albers et al., 2018), which themselves owe their propagation and breaking patterns to the strength and location of the subtropical and polar front jets (Hoskins and Ambrizzi, 1993; Scott and Cammas, 2002; Abatzoglou and Magnusdottir, 2006; Hitchman and Huesmann, 2007; Mundhenk et al., 2016; Olsen et al., 2019). For example, high TME is often observed on the western edge of blocking anticyclones in the North Pacific, where air is rising (Mundhenk et al., 2016), while STT occurs east of the block, where sinking air and PV intrusions frequently develop (Sprenger et al., 2007). This means that the variability and, as we will show, the predictability of both types of transport are dependent on the seasonal cycle of the Pacific jet.

Sometime between early March and late April, the Pacific jet undergoes a transition - which typically occurs very abruptly - from being strong and largely zonally contiguous between Asia and North America to being weak, with a discontinuity in the jet that spans most of the Pacific basin (Nakamura, 1992; Newman and Sardeshmukh, 1998; Hoskins and Hodges, 2019; Breeden et al., 2021). The characteristics of this transition, and its relationship to forms of low-frequency variability that might be predictable on subseasonal timescales (e.g., ENSO), have been explored in the context of the STT of mass and ozone. For example, Breeden et al. (2021) demonstrated that early-season jet transitions (mid-to-late March), which are more common during La Niña conditions, are characterized by enhanced mass transport to the PBL (see also, Lin et al., 2015, and references therein). Conversely, late transitions (mid-to-late April) have weaker transport to the PBL, although the association to El Niño is somewhat weaker. However, these analyses are retrospective, and it remains unclear whether forcings such as ENSO - and the resulting teleconnections - are actually forecast well enough to be useful when making subseasonal transport predictions.

While the predictability of mass transport on daily timescales is typically limited to less than 2 weeks (Lavers et al., 2016; DeFlorio et al., 2018), weekly averages of dynamical variables can occasionally have skill out to 36 weeks (e.g., Wang and Robertson, 2019; Buizza and Leutbecher, 2015; Albers and Newman, 2019). This evokes the possibility that forecasts of atmospheric transport, which may be harder for models to explicitly predict on subsea- 
STT to PBL
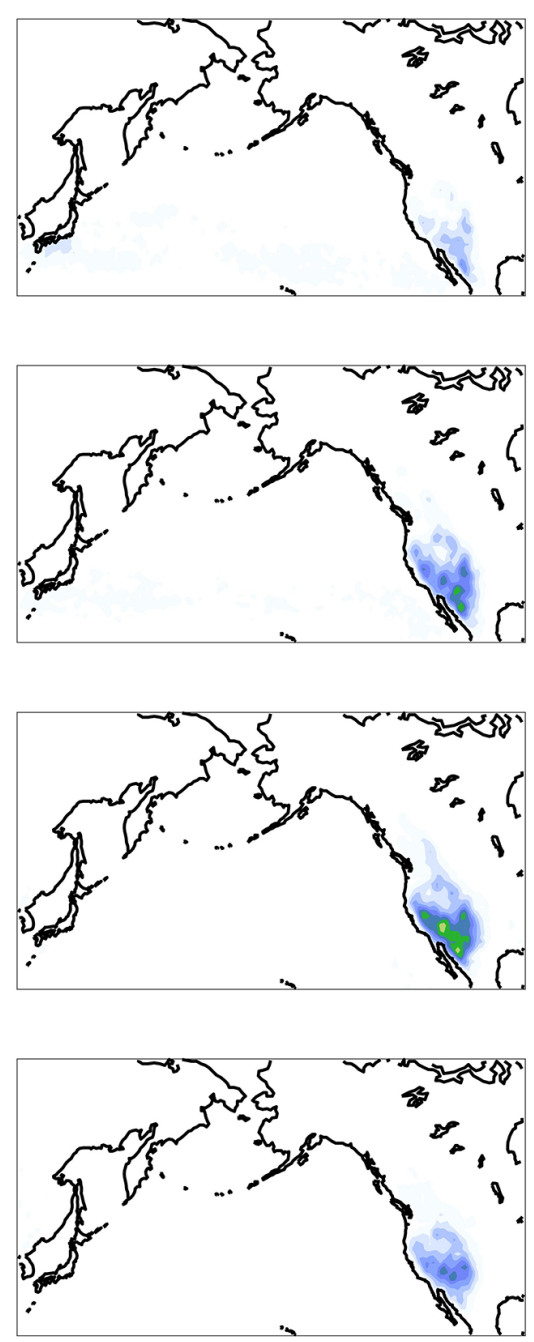

$130^{\circ} \mathrm{E} \quad 160^{\circ} \mathrm{E} \quad 190^{\circ} \mathrm{E} 220^{\circ} \mathrm{E} 250^{\circ} \mathrm{E}$
STT to $500 \mathrm{hPa}$
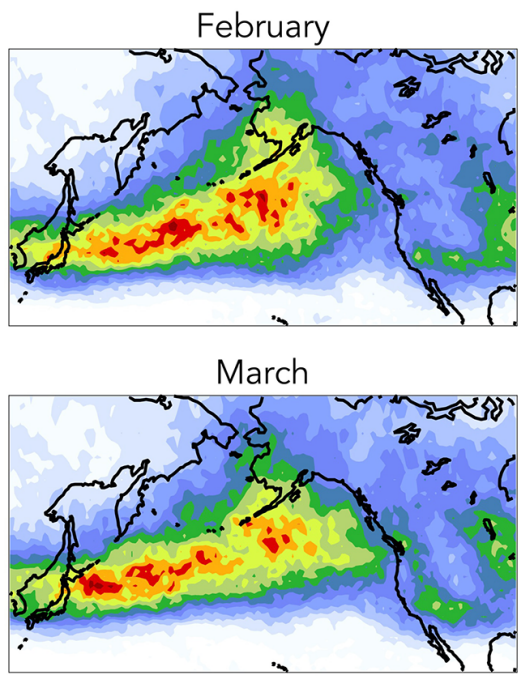

April
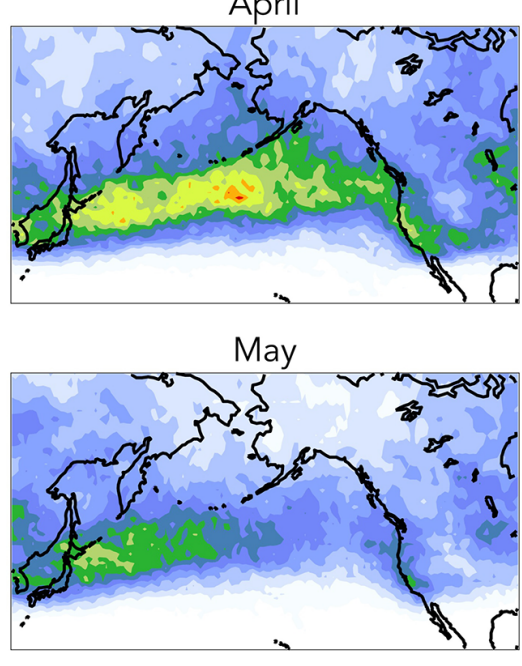

$130^{\circ}$ E $160^{\circ}$ E $190^{\circ}$ E $220^{\circ}$ E $250^{\circ}$ E
TME
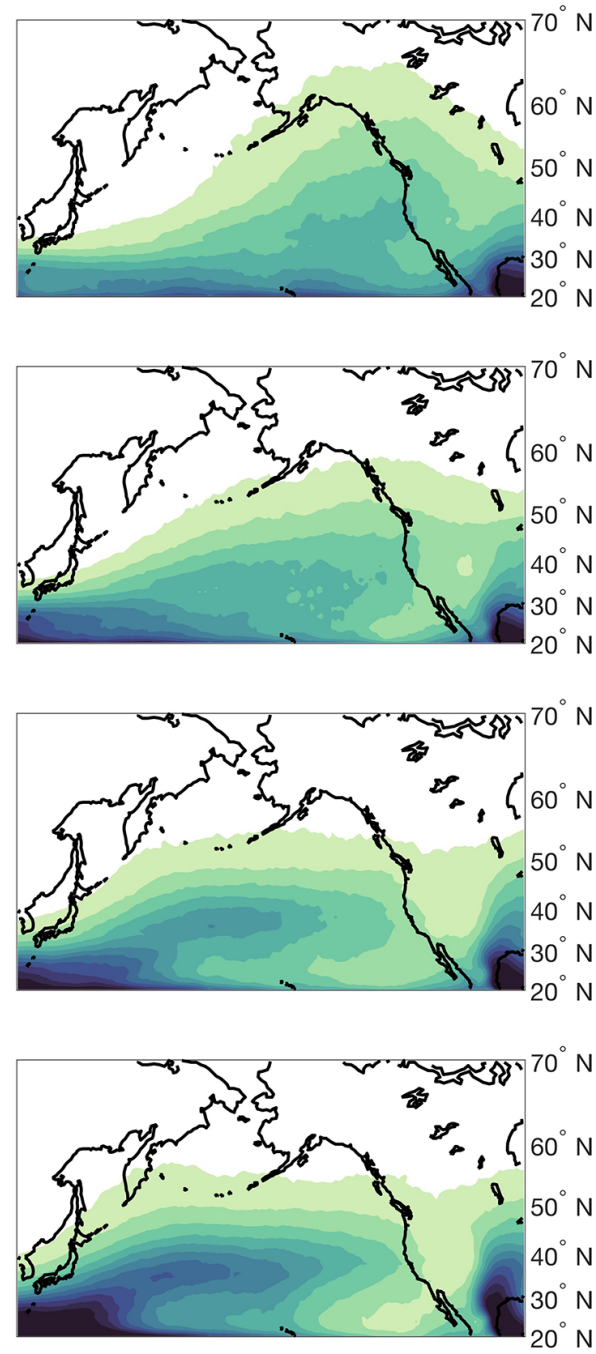

$130^{\circ} \mathrm{E} \quad 160^{\circ} \mathrm{E} 190^{\circ} \mathrm{E} 220^{\circ} \mathrm{E} 250^{\circ} \mathrm{E}$

Figure 1. Monthly average climatologies (1979-2014) of STT to the PBL (left column), STT to $500 \mathrm{hPa}$ (middle column), and TME (right column). Units for all panels are event frequencies (events/6-hourly time step), for which each of the relevant event types are defined in Sect. 2.2.

sonal timescales, might be successfully inferred from forecasts of more predictable or better constrained dynamical variables. Indeed, similar ideas have been successfully applied to assess the predictability of atmospheric blocking on seasonal timescales (Pavan et al., 2000) and precipitation on daily timescales (Lavers et al., 2014, 2016). Here we assess the potential predictability of transport during spring based on the predictability of zonal wind variance associated with the Pacific jet. We do so by considering a very simple conditional probability: if $200 \mathrm{hPa}$ zonal winds have a high (positive or negative) loading on a particular $200 \mathrm{hPa}$
Pacific basin zonal wind pattern, then what will the corresponding shift in the probability of STT or TME be during those time periods? We first answer this question in the context of a retrospective analysis (1979-2016), which allows us to understand the regionality of STT and TME for different jet patterns. Then, using the retrospective results as a guide, we utilize Subseasonal-to-Seasonal Prediction Project database (Vitart et al., 2017) zonal wind hindcasts (1997-2016) from the European Centre for Medium-Range Weather Forecasts (ECMWF) to test whether STT and TME over specific geographic regions may be predictable for sub- 
Table 1. Correlations between MAM monthly average PC time series and various climate indices with $p$ values in parentheses. The West Pacific pattern (WP), Pacific-North American pattern (PNA), and NOAA Oceanic Niño Index (ONI) are taken from NOAA Center for Weather and Climate Prediction (NOAA CPC).

\begin{tabular}{rrrr}
\hline & WP & PNA & ONI \\
\hline PC1 & $-0.66(0.00)$ & $0.44(0.00)$ & $0.16(0.1)$ \\
PC2 & $-0.38(0.00)$ & $-0.09(0.35)$ & $-0.78(0.00)$ \\
PC3 & $-0.31(0.00)$ & $-0.56(0.00)$ & $-0.05(0.64)$ \\
\hline
\end{tabular}

seasonal forecast leads (weeks 3-6). For both the retrospective and hindcast analyses, STT and TME are taken from the ETH-Zürich feature-based climatology database (available for years 1979-2016; Sprenger et al., 2017), which allows us to apply a single, self-consistent measure of transport for both the retrospective (1979-2016) and hindcast (19972016) analysis periods.

\section{Pacific jet and transport data}

\subsection{Jet variability}

Jet variability over the Pacific-North American region is represented via empirical orthogonal functions (EOFs), which are based on ERA-Interim (Dee et al., 2011) monthly mean (March-May, MAM) anomalies of $200 \mathrm{hPa}$ zonal wind (cosine latitude weighted $10-70^{\circ} \mathrm{N}$ and $125-270^{\circ} \mathrm{E}$ ) for the 1979-2016 period. Anomalies were created by removing the first four annual harmonics of the 1979-2016 daily climatology. Using monthly averages instead of daily or weekly values is motivated in part by the suggestion of Newman et al. (2012) that a large fraction of ocean-to-continent transport arises from low-frequency variability rather than individual synoptic events. Using monthly values also significantly boosts the variance explained by the leading three EOFs to nearly $60 \%$ vs. $<20 \%$ for daily values (e.g., Feldstein, 2000). We use a bootstrap method to test for EOF degeneracy (North et al., 1982) and find that the first three EOFs (Fig. A1), which represent $25 \%, 21 \%$, and $11 \%$ of the total MAM monthly mean wind variance, are reasonably well-separated and have robust spatial patterns (see Appendix for details). Hereafter we refer to the first three EOFs (and their corresponding principal component, $\mathrm{PC}$, time series) as EOF1 (PC1), EOF2 (PC2), and EOF3 (PC3).

While EOFs 1-3 are significantly correlated with several commonly used climate indices (Table 1), we make no inference that the EOF patterns represent dynamical or physical "modes" of the climate system (Monahan et al., 2009). Indeed, the significant correlations between each of our PC time series and multiple teleconnection indices indicates that the variance of our EOFs almost certainly results from a convolution of external forcing and internal variability across multiple timescales (e.g., Straus and Shukla, 2002). Evidence for this assertion can be found by noting that while EOF1 is essentially uncorrelated with the NOAA Oceanic Niño In$\operatorname{dex}(\mathrm{ONI})$ (correlation of 0.16 and not significant), EOF1 is 1-month lag correlated with EOF2 (correlation 0.66, significance level $>95 \%$ ), which is itself highly correlated with the ONI index (correlation 0.78, significance level $>95 \%$ ). Thus, with one exception (considered in the Discussion) we simply use the EOFs as a data compression tool that helps to isolate the largest-scale flow patterns that we anticipate will have the best chance for prediction.

To evaluate the potential predictability of Pacific jet variability, we use hindcasts (1997-2016) of $200 \mathrm{hPa}$ zonal wind from the European Centre for Medium-Range Weather Forecasting Integrated Forecasting System (ECMWF IFS CY43R1/R3, model operational in 2017) which were obtained from the Subseasonal-to-Seasonal Prediction Project database (Vitart et al., 2017). Hindcasts are "coarse-grained" in time via a $7 \mathrm{~d}$ running-mean and in space via regridding to a fixed $2.5^{\circ}$ latitude/longitude grid. Anomalies are computed by removing the lead dependent climatology, which also serves as a mean bias correction (e.g., Buizza and Leutbecher, 2015; Monhart et al., 2018). Hindcasts are computed as 3-week averages for weeks 3-5 (i.e., days 15-35). The 3week averages are then projected onto the EOF patterns described above. We also computed results for other averaging periods including weeks $3-4$ and $3-6$, as well as individual week 3,4 , and 5 forecasts, but settled on weeks $3-5$ because we found that this window provided the most skillful transport forecasts. Specifically, averaging several weeks together increased skill (i.e., an extension of the "forecast skill horizon"; see, for example, Younas and Tang, 2013; Buizza and Leutbecher, 2015), while extending the forecast window out all the way to week 6 degraded forecast skill because the forecast zonal wind anomaly amplitudes become very small compared to the verification anomaly amplitudes. The IFS hindcast PC time series are verified against ERA-Interimbased PC time series prepared in an identical manner.

To help verify that the zonal wind EOF patterns are highlighting Pacific jet variability (in Sect. 3.1), we compare the EOFs to a upper tropospheric jet stream climatology (Koch et al., 2006; Sprenger et al., 2017), which is itself based on ERA-Interim. The jet climatology (1979-2014) is based upon the vertical averaging of zonal and meridional winds between $100-500 \mathrm{hPa}$ at every horizontal grid point, where a "jet event" at each grid point is detected when the vertically averaged wind exceeds $30 \mathrm{~m} \mathrm{~s}^{-1}$. This procedure yields a frequency of upper tropospheric jet events at each grid point.

\subsection{Transport composites}

To examine stratosphere-to-troposphere mass transport and tropical-to-extratropical water vapor transport, we use six ETH-Zürich feature-based ERA-Interim climatologies (Sprenger et al., 2017): stratosphere-to-troposphere mass 
transport to $500 \mathrm{hPa}\left(\mathrm{STT}_{500}\right)$, which provides an estimation of transport into the free troposphere, stratosphereto-troposphere transport to the planetary boundary layer (STTPBL) (Sprenger et al., 2003; Škerlak et al., 2014), and a climatology of tropical-to-extratropical moisture export (TME), (Knippertz and Wernli, 2010). The STT climatologies (1979-2016) are based on Lagrangian parcel trajectories calculated using the LAGRANTO Lagrangian transport model (Wernli and Davies, 1997; Sprenger and Wernli, 2015), in which stratosphere-to-troposphere mass trajectories are considered as exchange "events" if they have $48 \mathrm{~h}$ stratospheric, followed by $48 \mathrm{~h}$ tropospheric, residence times. We use both monthly mean and daily mean climatologies of $\mathrm{STT}_{500}$ and $\mathrm{STT}_{\mathrm{PBL}}$, all of which have units of number of mass exchange events per 6-hourly time step. TME climatologies (1979-2016) are calculated via LAGRANTO water mass trajectories that originate in the tropics and reach at least $35^{\circ} \mathrm{N}$ with a water mass flux greater than $100 \mathrm{~g} \mathrm{~kg}^{-1} \mathrm{~m} \mathrm{~s}^{-1}$; we use monthly mean and daily mean TME climatologies in which units are given as the number of TME events per 6-hourly time step.

For our retrospective transport analysis, we composite STT and TME for months when the zonal-wind PC time series were larger than $1 \mathrm{SD}$. For the hindcasts, we use a slightly weaker $0.8 \mathrm{SD}$ threshold in order to boost the number of samples given the relatively short length of the subseasonal-to-seasonal hindcast database (1997-2016). We chose to keep the SD threshold as high as possible though because higher amplitude anomalies likely correspond to periods of higher forecast skill (Compo and Sardeshmukh 2004; Van den Dool and Toth 1991; Johansson 2007). Importantly, the choice of threshold does not qualitatively change our results. Hindcast transport composites are based on time periods when weekly average forecasts of zonal-wind PC time series were predicted to exceed $0.8 \mathrm{SD}$. For hindcast verification composites, the composites are based on periods when the verification weekly average zonal-wind PC time series exceeded $0.8 \mathrm{SD}$. This procedure typically means that the verification composites include more samples because, as we will show, the weeks 3-5 IFS forecasts systematically underestimate the amplitude of the zonal wind PC time series and thus do not exceed the SD threshold as often as is observed.

We also briefly discuss the connection between STT and climatologies of tropopause folds (Sprenger et al., 2003; Škerlak et al., 2014), PV streamers (Wernli and Sprenger, 2007), and PV cutoffs (Wernli and Sprenger, 2007). Tropopause folds are defined as regions where a vertical profile contains three crossings of the dynamical tropopause, with additional criteria applied to ensure that the folded air mass is "stratospheric" (e.g., enclosed air mass must have PV $>2 \mathrm{PV}$ units and cannot be of diabatic origin). Shallow, medium, and deep tropopause folds were considered, but only shallow and medium depth folds were found to be relevant. PV streamers (thin filaments of stratospheric air) are identified using a geometric contour searching al- gorithm, while PV cutoffs are identified as stratospheric air masses (PV $>2$ PV units) that are isolated and fully embedded within the troposphere. PV streamers and cutoffs were considered on isentropic surfaces between $305-340 \mathrm{~K}$, but only the most relevant surfaces are shown. Units for folds, streamers, and cutoffs are events per 6-hourly time step.

\subsection{Units and significance testing}

While the original units of all of the ETH-Zürich climatologies are frequencies (jet frequency, STT, tropopause folds, PV streamers, PV cutoffs, and TME), all of our figures, except for the climatologies (Fig. 1), are presented in units of standard deviations. That is, for every variable, we calculate anomalies from climatology and then divide by the anomaly standard deviation ( $z$ scoring). Thus, a unit of "1 SD" equates to a 1 standard deviation anomaly, for which the standard deviation is calculated individually for each specific time period considered (e.g., the SD normalization for a March monthly mean is different from the SD normalization used for a 3-week forecast period in March).

When comparing forecast and verification transport probability density functions (PDFs), we evaluate significance via a combination of bootstrap confidence intervals (10000 ensembles with replacement) and two-sample KolmogorovSmirnov distribution tests (KS-test; Marsaglia et al., 2003; Hollander et al., 2013), in which the latter tests whether the shape and location of two empirical distributions are significantly different. The PDFs themselves are created by taking box-area means of STT or TME for a specified geographic region at every forecast time step and using each as a "sample". The PDFs are then calculated via kernel density estimation based on the collection of all samples for either the forecasts or verifications.

\section{Results}

\subsection{Retrospective analysis}

The first three EOF patterns of the $200 \mathrm{hPa}$ zonal wind all exhibit anomalies that correspond to some amount of extension or retraction and/or latitudinal shifting of the Pacific jet compared to climatology (Fig. 2). This interpretation is confirmed by compositing ETH-Zürich feature-based jet frequencies for time periods with high EOF loading (PC amplitude $>1 \mathrm{SD}$ ), which yields jet frequency distributions that correspond extremely well with each of the first three EOF wind patterns (Fig. S1 in the Supplement). This suggests that the amount of wind variance explained by each of the individual EOFs is sufficiently large that when the PC magnitude is high, there are notable corresponding shifts in the location of the Pacific jet stream. While the EOF patterns likely combine jet variability due to both the subtropical and polar front jets (Koch et al., 2006), a strong jet stream of either type will act as a waveguide for Rossby waves (e.g., Schwierz 
et al., 2004; Rivière, 2010, and references therein) with an increased frequency of STT (e.g., Shapiro and Keyser, 1990) and TME (e.g., Higgins et al., 2000; Sprenger et al., 2017).

To evaluate the jet-transport connection, we consider STT and TME for time periods with high zonal wind EOF loading (absolute value of PCs > 1 SD). Because the patterns of the STT and TME anomaly composites are so similar for both EOF phases, we show only the negative EOF pattern; see Figs. S2-S4 in the Supplement for the positive phase. STT 500 maxima match the EOF wind patterns quite well (Fig. 3, top row), with positive (negative) STT $_{500}$ anomalies tending to occur along the northern flanks of the regions of stronger (weaker) winds (Koch et al., 2006) and hence increased (decreased) jet frequency. The correspondence of higher $\mathrm{STT}_{500}$ with higher wind speeds suggests that transverse circulations around the jet play a key role in transport and confirms that the EOF-based STT $_{500}$ anomalies are related to variations in the North Pacific storm track (Škerlak et al., 2014). The STT $_{500}$ anomalies are most closely associated with shallow to medium depth tropopause folds (Figs. S5 and S6 in the Supplement) and PV cutoffs along the $310 \mathrm{~K}$ isentropic surface (Fig. S7 in the Supplement).

$\mathrm{STT}_{\mathrm{PBL}}$, on the other hand (Fig. 3 middle row), has maxima slightly downstream of the $500 \mathrm{hPa}$ maxima, which reflects the fact that deep STT tends to occur as maturing Rossby waves amplify and PV streamers become increasingly stretched and filamented along isentropic surfaces that slope equatorward and downwards towards the surface (see, for example, discussion of Fig. 5 in Škerlak et al., 2014; see also Reed and Danielson, 1958; Shapiro, 1980; Shapiro and Keyser, 1990; Wernli and Bourqui, 2002; Sprenger et al., 2003; Appenzeller et al., 1996; Wernli and Sprenger, 2007). In addition, as the PV streamers become more filamented, isolated regions of high PV stratospheric air often become fully detached as PV cutoffs. Indeed, MAM STT $\mathrm{PBL}_{\text {appears }}$ to be closely associated with PV streamers and PV cutoffs along the 310 and $305 \mathrm{~K}$ isentropic surfaces (Figs. S8 and S9 in the Supplement, respectively). In contrast to $\mathrm{STT}_{500}$, STT $_{\mathrm{PBL}}$ does not appear to be strongly associated with tropopause folds (not shown; see also Fig. S1e in the Supplement of Škerlak et al., 2015), though some caution should be exercised when interpreting the relative importance of tropopause folds, PV streamers, and PV cutoffs for deep STT as shown here because previous authors, using alternative techniques, have found that tropopause folds play an important role in deep STT (e.g., Shapiro, 1980; Langford et al., 2009; Breeden et al., 2021, and references therein). Anomalous TME also corresponds well with the EOF patterns (Fig. 3, bottom row) except that the anomalies are on the southern edge of the positive EOF wind patterns, which is due to the tendency for strong TME to occur along the warm sector of a breaking Rossby wave (Bao et al., 2006; Knippertz et al., 2013).

While all of the transport composites are physically consistent with the EOF patterns, and hence jet variability, the
STT $_{500}$ and TME composites have a much more robust signal compared to $\mathrm{STT}_{\mathrm{PBL}}$. That the $\mathrm{STT}_{\mathrm{PBL}}$ is weaker is not entirely surprising because while a high percentage of upper level breaking waves extend downwards to the middle to upper troposphere, subsequently causing associated $\mathrm{STT}_{500}$ and TME, only a small subset of these waves will achieve the needed amplitude and depth to extend all the way to the PBL. Moreover, transport to the STT $\mathrm{PBL}_{\mathrm{PL}}$ is also dependent on the depth of the PBL, which tends to be relatively shallow until late spring to early summer when convective heating begins to increase (Seidel et al., 2012; Škerlak et al., 2014; Breeden et al., 2021). Nevertheless, all of the composites provide a basis for the expectation that Pacific jet variability can be used as a predictor for transport over landmasses of interest, including the western United States, southern Alaska, and Japan.

\subsection{Potential predictability of jet shifts and transport}

While subseasonal forecasts of teleconnection indices are known to exhibit reasonable correlation-based skill (Wang and Robertson, 2019), the amplitude of the anomalies is often quite weak compared to observations (Yamagami and Matsueda, 2020). Thus, the relevant question here is, do forecast models predict jet variability well enough - in terms of both correlation and anomaly amplitude - to provide guidance for subseasonal transport forecasting?

For weekly forecasts, the correlation between the forecasted and verified zonal wind PCs is "skillful" (correlations > 0.5-0.6; Hollingsworth et al., 1980; Arpe et al., 1985; Murphy and Epstein, 1989) within the deterministic timeframe (weeks 1-2) for all three EOFs (Table 2). Beyond week 2, however, the PC1 and PC3 correlations drop off rapidly, with the skill of predicting PC3 almost completely limited to synoptic timescales. On the other hand, PC2 retains useful skill all the way out to forecast week 6 , which may be due to its stronger relationship to ENSO (Table 1). These correlations suggest that only the first two PCs retain enough skill to be useful on subseasonal leads. The same result is true for the weeks 3-5 forecast window (Fig. 4), for which forecast-verification correlations for both PC1 and PC2 are near or above 0.5 , while PC3 exhibits very low correlation-based skill. In terms of the PC amplitudes of the weeks 3-5 forecasts, both PC1 and PC2 regularly exceed our 0.8 SD threshold, while the PC 3 amplitude rarely exceeds it. Thus, while EOF3 is related to large transport anomalies over land regions of interest (e.g., STT $\mathrm{PBL}$ and TME over North America), it is unfortunately not predictable on subseasonal timescales (similar results are also found for EOFs 4 and higher). We therefore focus on predicting transport via PC1 and $\mathrm{PC} 2$.

The number of observed instances (verifications) when the PC1 and PC2 amplitudes exceed 0.8 SDs exhibits a seasonal cycle (Fig. 5), though the degree of overlap of the confidence intervals suggests that the seasonal cycle is more pro- 

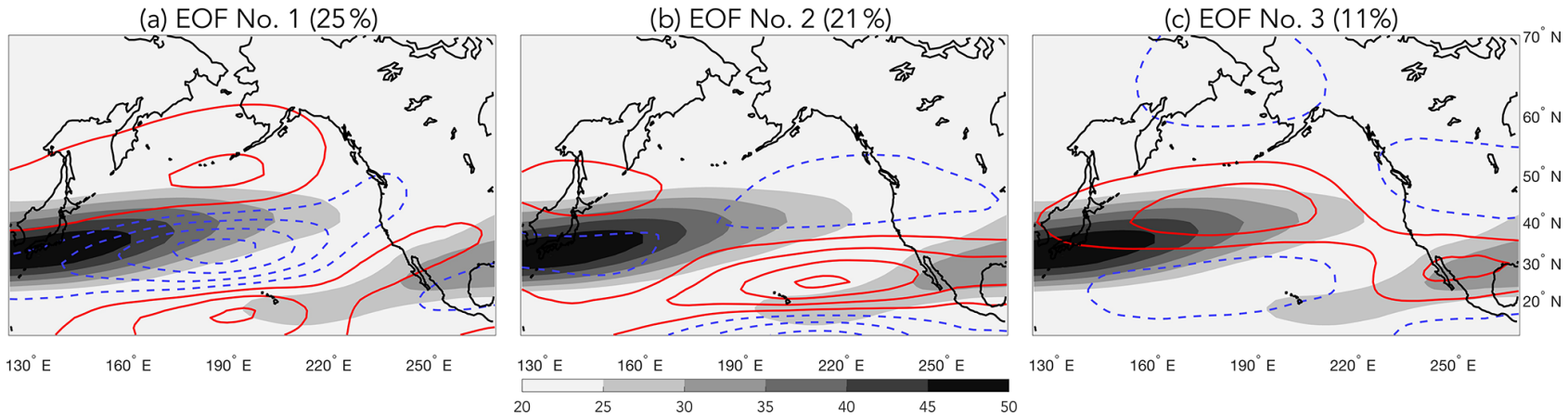

Figure 2. Spring (MAM, 1979-2014) zonal wind climatology (filled contours) with colored contours showing the first three EOF patterns. The variance explained by each EOF is shown in the title for each panel. Units of the zonal wind climatology are meters per second ( $\mathrm{m} \mathrm{s}^{-1}$ ). The EOF zonal wind anomaly contours span \pm 1 to 7 in $2 \mathrm{~ms}^{-1}$ intervals.

EOF No. 1
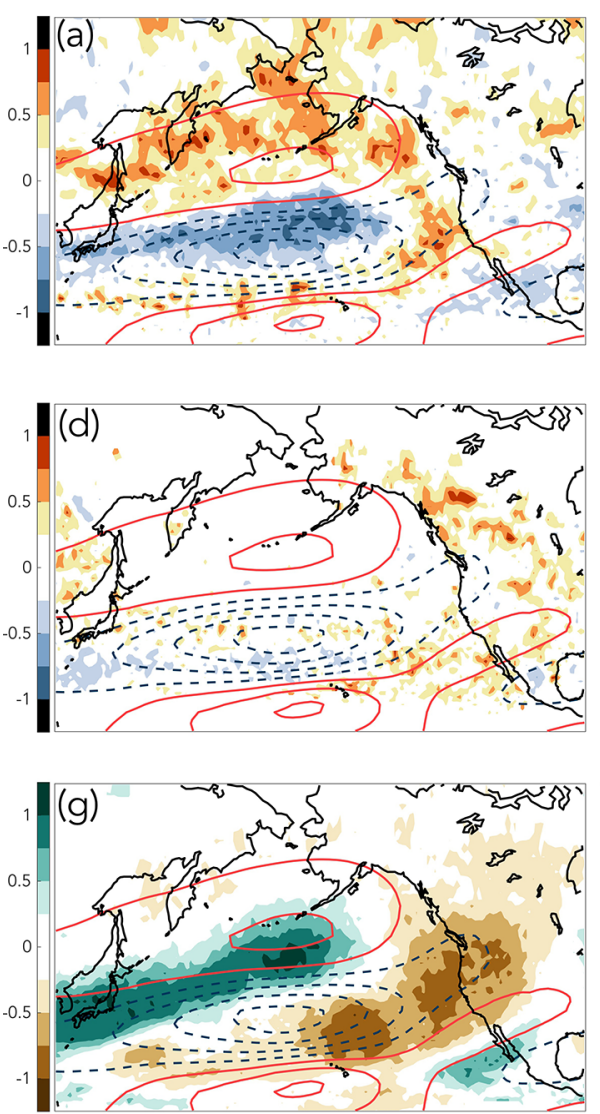

$130^{\circ} \mathrm{E} \quad 160^{\circ} \mathrm{E} \quad 190^{\circ} \mathrm{E} \quad 220^{\circ} \mathrm{E} \quad 250^{\circ} \mathrm{E}$
EOF No. 2

STT to $500 \mathrm{hPa}$

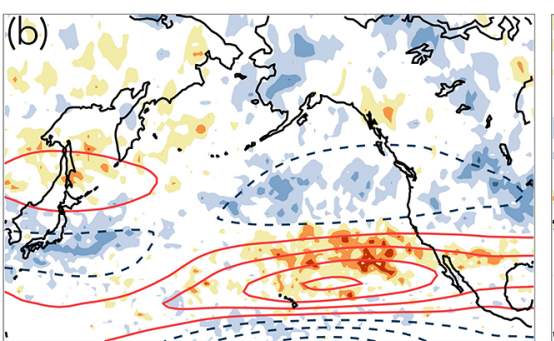

$\mathrm{STT}$ to PBL

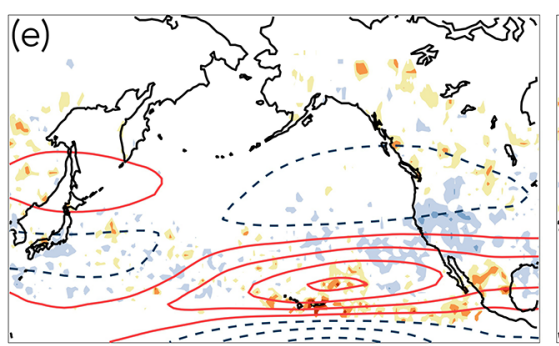

TME

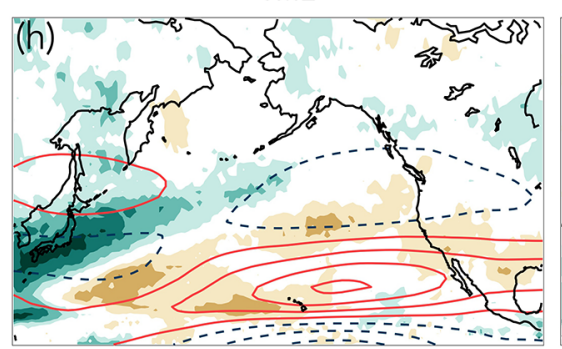

$130^{\circ} \mathrm{E}-160^{\circ} \mathrm{E} \quad 190^{\circ} \mathrm{E}-220^{\circ} \mathrm{E}=250^{\circ} \mathrm{E}$
EOF No. 3
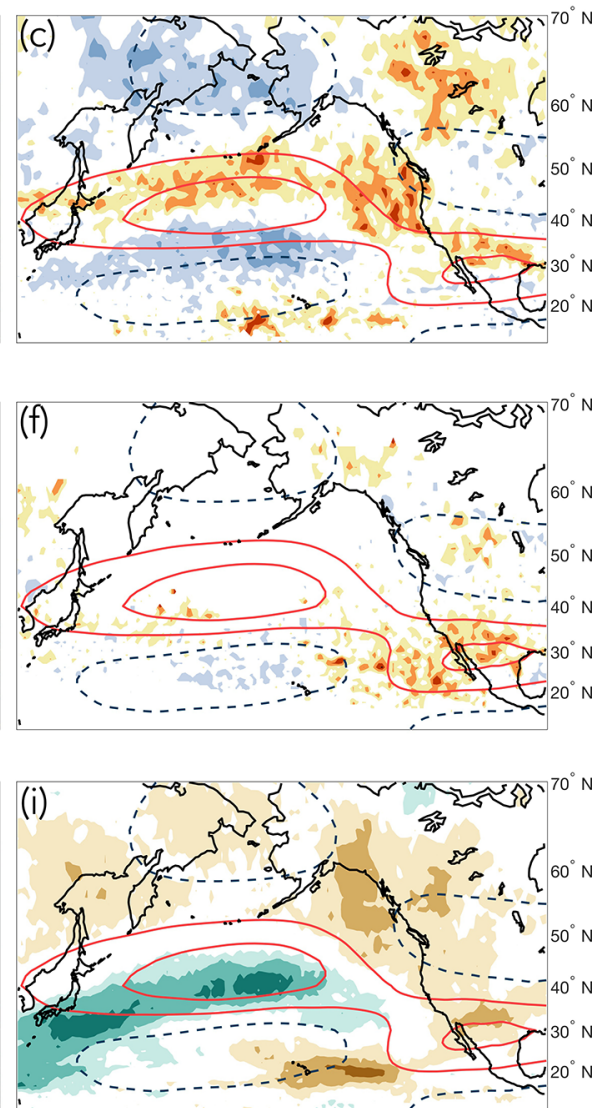

$130^{\circ} \mathrm{E} \quad 160^{\circ} \mathrm{E} \quad 190^{\circ} \mathrm{E} \quad 220^{\circ} \mathrm{E} \quad 250^{\circ} \mathrm{E}$

Figure 3. Monthly mean (MAM, 1979-2014) frequencies (filled contours) of STT to $500 \mathrm{hPa}(\mathbf{a}-\mathbf{c})$, STT to the PBL (d-f), and TME (g-i) for time periods when PCs 1-3 are greater than 1 SD from climatology for the negative EOF phase (units of SDs). Colored contours show the EOF patterns associated with each composite. See Figs. S2-S4 for composites of the positive EOF phase. 
Table 2. Correlations between MAM weekly average PC time series of IFS hindcasts and ERA-Interim verifications. The 95th percentile confidence intervals are shown in square brackets underneath each correlation coefficient. All $p$ values are less than 0.05 when all data are used in the forecast-verification correlation calculations; however, if the correlation calculations are repeated instead using every third forecast (to take into account autocorrelation in the forecast time series), then PC3 has large $p$ values $(0.12$ and 0.32$)$ at weeks 5 and 6 , respectively, while all other PC correlations at all forecast leads remain $<0.05$.

\begin{tabular}{rrrrrrr}
\hline & Week 1 & Week 2 & Week 3 & Week 4 & Week 5 & Week 6 \\
\hline PC 1 & $0.97[0.96,0.97]$ & $0.78[0.75,0.83]$ & $0.57[0.51,0.63]$ & $0.42[0.35,0.49]$ & $0.3[0.22,0.38]$ & $0.31[0.23,0.39]$ \\
PC 2 & $0.97[0.96,0.98]$ & $0.86[0.84,0.88]$ & $0.74[0.7,0.78]$ & $0.71[0.66,0.75]$ & $0.68[0.63,0.72]$ & $0.66[0.61,0.71]$ \\
PC 3 & $0.94[0.93,0.95]$ & $0.68[0.63,0.72]$ & $0.38[0.3,0.45]$ & $0.21[0.13,0.3]$ & $0.12[0.03,0.2]$ & $0.09[0.0,0.18]$ \\
\hline
\end{tabular}

(a) EOF 1

[Correlation; Confidence Interval] $=[0.49 ; 0.42,0.55]$

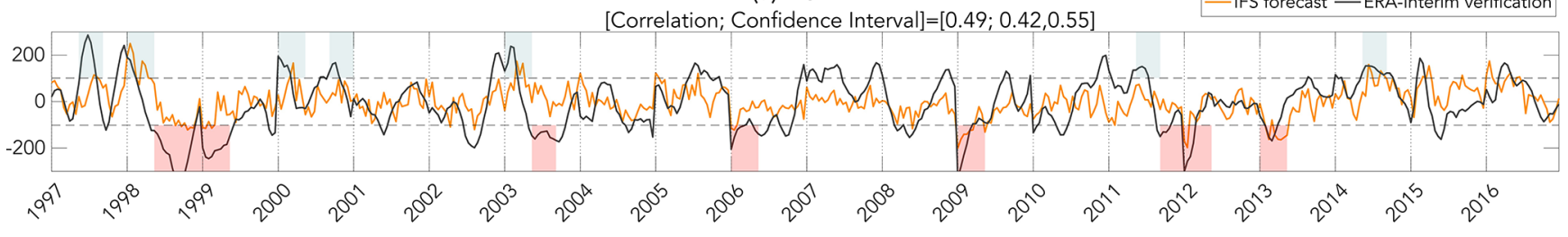

(b) EOF 2

[Correlation; Confidence Interval] $=[0.81 ; 0.77,0.83]$

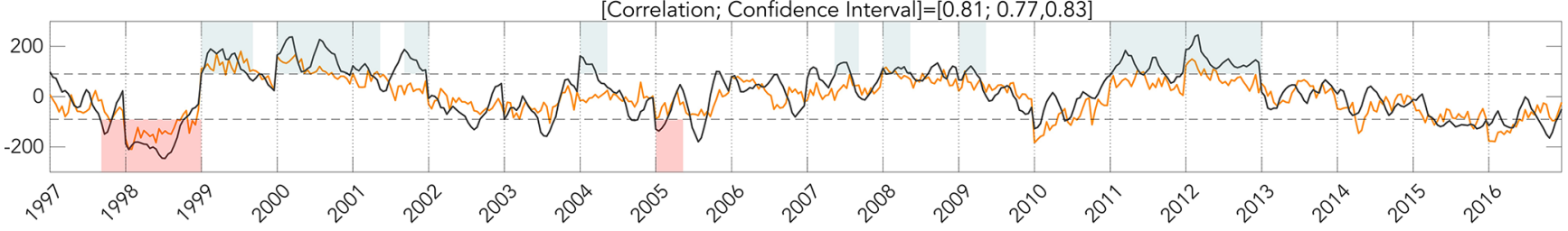

(c) EOF 3

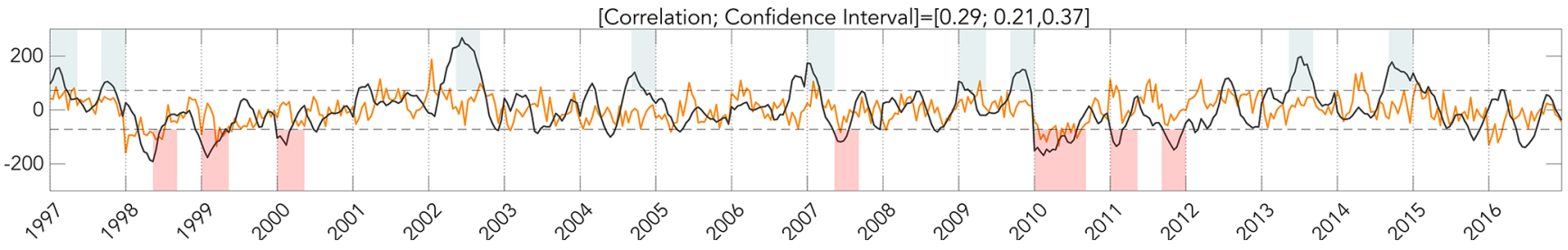

Figure 4. Time series of weeks 3-5 average zonal wind projected onto EOFs 1-3 for IFS forecasts (orange lines) and ERA-Interim verifications (black lines). The horizontal dashed lines denote $\pm 0.8 \mathrm{SDs}$ from the mean of the verification time series. For reference, the light blue and red shading denote the months that were included in the monthly average composites used to create Fig. 3. Correlations between the forecasts and verifications (with 95th percentile confidence intervals) are shown in the titles of each panel.

nounced for EOF2 than for EOF1. The situation is a bit more complicated if the individual phases of each EOF are considered (see Fig. S10 in the Supplement), though the small sample sizes make conclusive inferences difficult. Nevertheless, the slow decay of observed PC1 and PC2 exceedances (i.e., large amplitude jet events) between March and May is qualitatively consistent with previous studies documenting the seasonality of jet activity and Pacific baroclinic wave amplitudes (Nakamura, 1992; Koch et al., 2006). Unfortunately, the number of PC1 and PC2 exceedances predicted by the IFS at 3-5 week lead times has a much stronger seasonal cycle compared to observations, with early spring having many more exceedances than for late spring for both phases of PC1 and PC2 (Figs. 5 and S10). This implies that the transport anomalies outlined next are more predictable, and hence the composites more heavily weighted, for the periods before the jet undergoes its spring transition (Newman and Sardeshmukh, 1998; Breeden et al., 2021).

Based on the regions with the largest transport anomalies (Fig. 3) for the more predictable PC1 and PC2 time series (Fig. 4), we chose four subregions within the full $\mathrm{Pa}$ cific domain to examine the potential predictability of STT and TME: EOF1-based STT $_{500}$ for the North Pacific, which includes southern Alaska and the Russian Far East; EOF2based STT $_{\mathrm{PBL}}$ for the western to intermountain-western United States; EOF1-based TME for the western United States; and EOF2-based TME for the West Pacific (Japan and far eastern Asia). These subregions are highlighted by the boxes in Figs. 6a, 7a, 8a, and 9a, respectively. To provide context for the four subregion forecasts, we first show fore- 

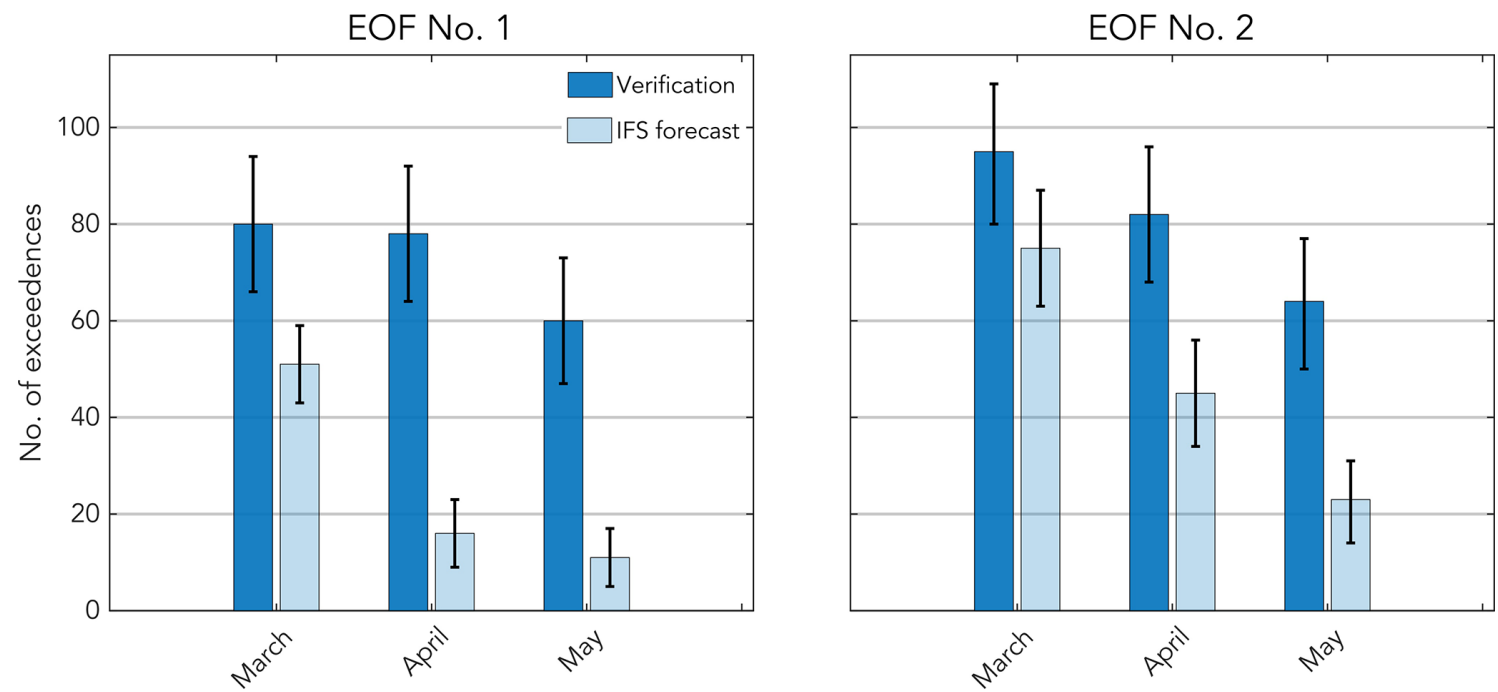

Figure 5. Number of times that a weeks 3-5 average verification or forecast exceeded the 0.8 SD threshold for the 1997-2016 hindcast period (i.e., the periods in Fig. 4 when the black or orange lines, respectively, were above or below the dashed horizontal SD reference lines). The 95th percentile bootstrap confidence intervals are shown as whiskers.

EOF1-based STT to $500 \mathrm{hPa}$

(a) Verification positive phase

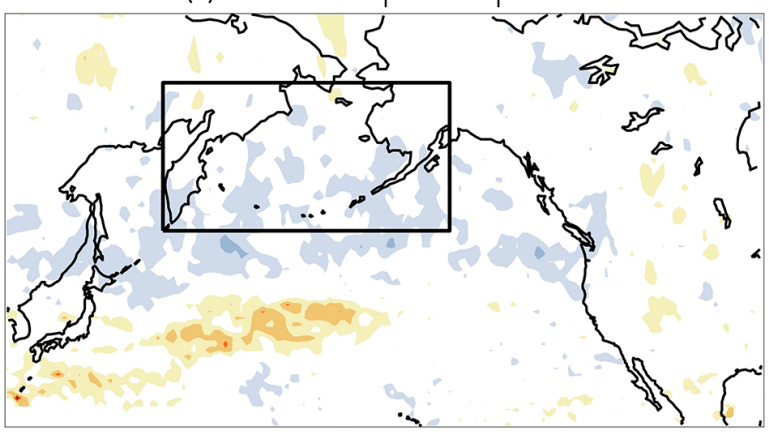

(c) Forecast positive phase $(0.49)$

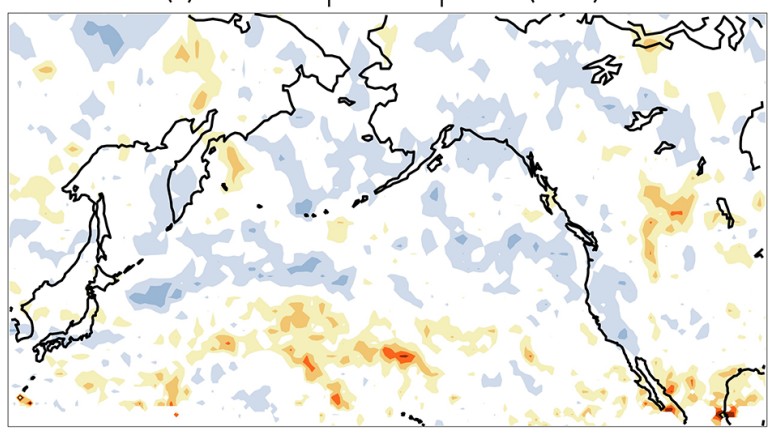

$130^{\circ} \mathrm{E} \quad 150^{\circ} \mathrm{E} \quad 170^{\circ} \mathrm{E} \quad 190^{\circ} \mathrm{E} \quad 210^{\circ} \mathrm{E} \quad 230^{\circ} \mathrm{E} \quad 250^{\circ} \mathrm{E} \quad 270^{\circ} \mathrm{E}$ (b) Verification negative phase

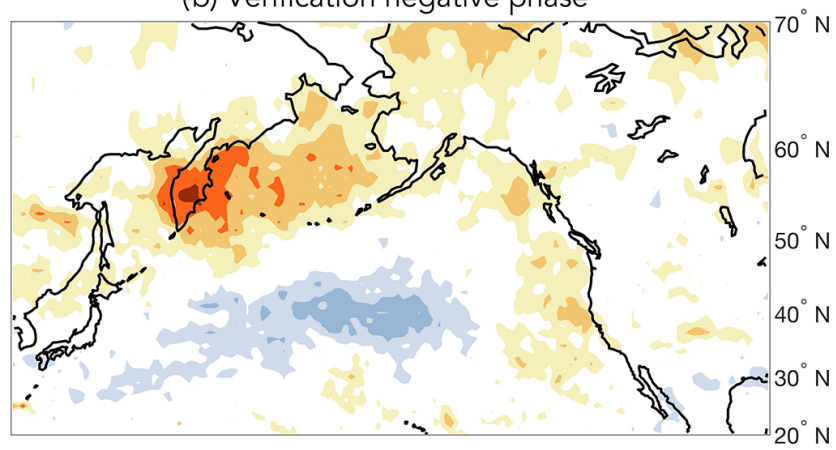

(d) Forecast negative phase (0.75)

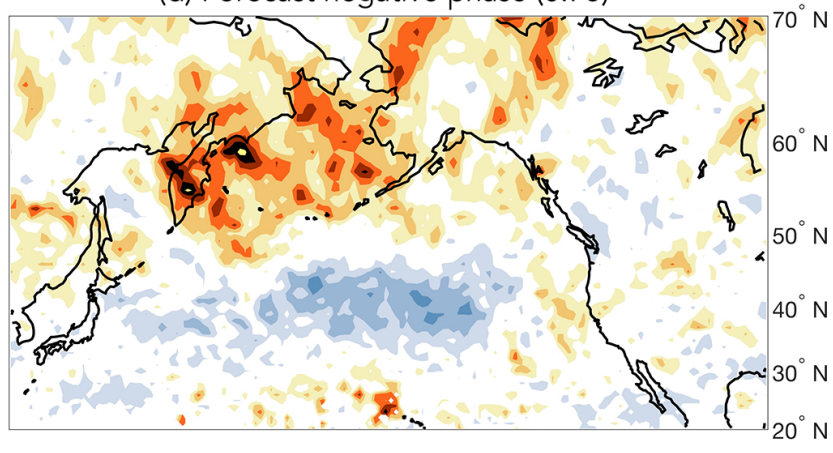

$130^{\circ} \mathrm{E} \quad 150^{\circ} \mathrm{E} \quad 170^{\circ} \mathrm{E} \quad 190^{\circ} \mathrm{E} \quad 210^{\circ} \mathrm{E} \quad 230^{\circ} \mathrm{E} \quad 250^{\circ} \mathrm{E} \quad 270^{\circ} \mathrm{E}$

$-1.5$

$-1$

$-0.5$

0

0.5

1

1.5

Figure 6. (a, b) EOF1-based composites of STT to $500 \mathrm{hPa}$ for weeks 3-5 forecast periods when the verification time series (black line in Fig. 4) was above (positive phase) or below (negative phase) the $0.8 \mathrm{SD}$ threshold. (c, d) EOF1-based composites of STT to 500 hPa for weeks 3-5 forecast periods when the forecast time series (orange line in Fig. 4) was above (positive phase) or below (negative phase) the 0.8 SD threshold. The black box outlines the North Pacific subregion used for creating the transport PDF in Fig. 10a. Units are in SDs, and pattern correlations between top and bottom panels (cf., a vs. $\mathbf{c}$ and $\mathbf{b}$ vs. d) are shown in the bottom row titles. 
EOF2-based STT to PBL

(a) Verification positive phase

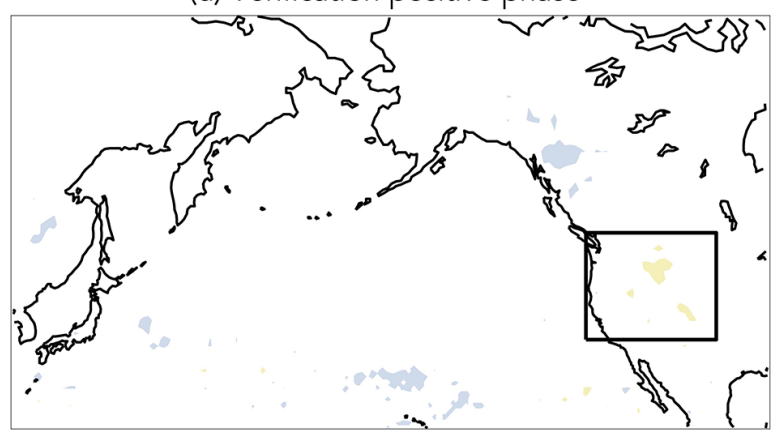

(c) Forecast positive phase $(0.87)$

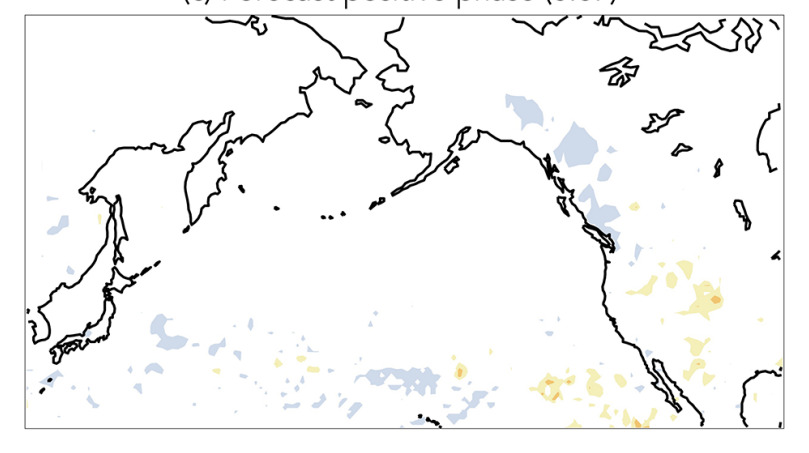

(b) Verification negative phase

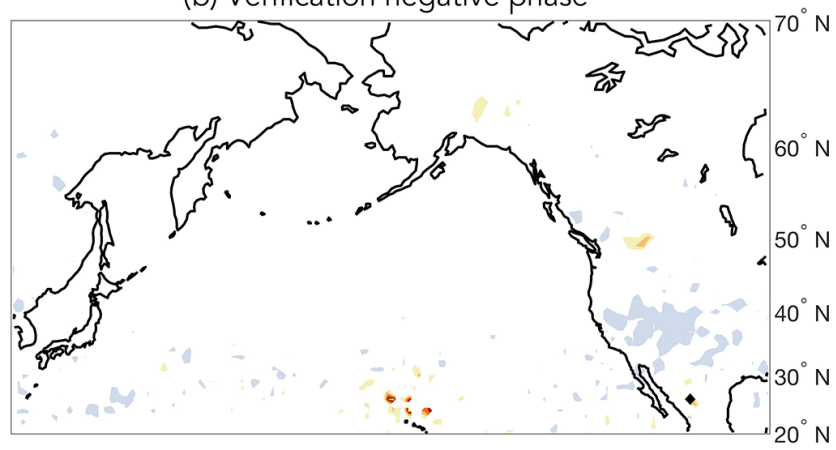

(d) Forecast negative phase (-0.2)

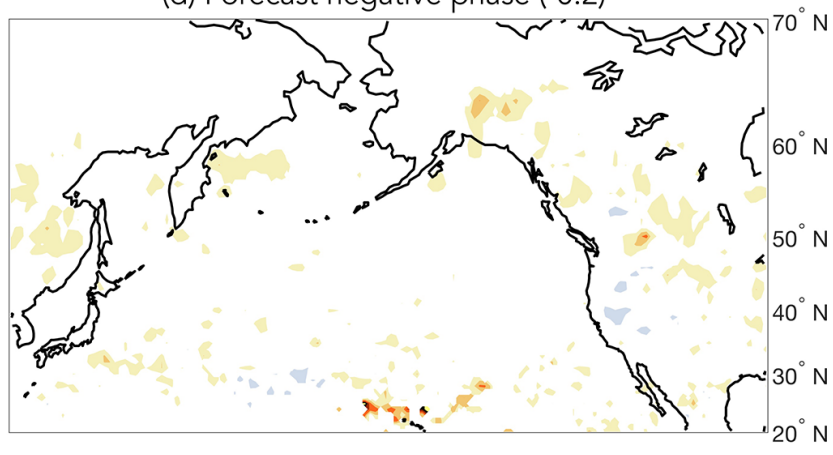

$130^{\circ} \mathrm{E} \quad 150^{\circ} \mathrm{E} \quad 170^{\circ} \mathrm{E} \quad 190^{\circ} \mathrm{E} \quad 210^{\circ} \mathrm{E} \quad 230^{\circ} \mathrm{E} \quad 250^{\circ} \mathrm{E} \quad 270^{\circ} \mathrm{E}$

$130^{\circ} \mathrm{E} \quad 150^{\circ} \mathrm{E} \quad 170^{\circ} \mathrm{E} \quad 190^{\circ} \mathrm{E} \quad 210^{\circ} \mathrm{E} \quad 230^{\circ} \mathrm{E} \quad 250^{\circ} \mathrm{E} \quad 270^{\circ} \mathrm{E}$

$-1.5$

$-1$

$-0.5$

0

0.5

1

1.5

Figure 7. (a, b) EOF2-based composites of STT to the PBL for weeks 3-5 forecast periods when the verification time series (black line in Fig. 4) was above (positive phase) or below (negative phase) the 0.8 SD threshold. (c, d) EOF2-based composites of STT to the PBL for weeks 3-5 forecast periods when the forecast time series (orange line in Fig. 4) was above (positive phase) or below (negative phase) the $0.8 \mathrm{SD}$ threshold. The black box outlines the western to intermountain-western US subregion used for creating the transport PDF in Fig. 10b. Units are in SDs, and pattern correlations between top and bottom panels (cf., a vs. $\mathbf{c}$ and $\mathbf{b}$ vs. d) are shown in the bottom row titles.

cast and verification transport anomalies for the entire Pacific domain. For each of the four full domain figures (Figs. 69), the top two panels show verification transport composites which are based on times when the verification zonal wind PC time series amplitude is greater than \pm 0.8 SD (black lines in Fig. 4), while the bottom two panels show corresponding transport composites except for time periods when the forecasted zonal wind PC time series amplitude is greater than $\pm 0.8 \mathrm{SD}$ (orange lines in Fig. 4). For comparison, the months that are included in the retrospective composites (Fig. 3) are highlighted by the light red and blue shading in Fig. 4 (note that the time periods when the week 3-5 time series exceed the $\pm 0.8 \mathrm{SD}$ threshold do not always match the red and blue shading regions because the shaded regions highlight periods when the monthly mean time series exceeded the monthly $1 \mathrm{SD}$ threshold). The pattern correlations between the forecast and verification transport composites for the full domains in Figs. 6-9 (not just for the boxed-in areas) are included in the forecast titles for both EOF phases. Transport predictability for the four boxed subregions is subsequently evaluated via PDFs of transport for the forecasts and verifications (Fig. 10). Beyond the four region- and transport-type combinations just mentioned, $\mathrm{STT}_{500}$ and TME were found to be potentially predictable for EOFs 1 and 2 over several additional subregions of the central Pacific basin, but because those results are similar to what we discuss below, they are not shown.

$\mathrm{STT}_{500}$ based on the EOF1 forecast is qualitatively consistent with the verification-based composite for both positive and negative EOF phases (Fig. 6), though the $\mathrm{STT}_{500}$ pattern is better reproduced for the negative phase (pattern correlation of 0.49 vs. 0.75 for the positive vs. negative phases, respectively). In addition, the verification composites show an asymmetry between opposite EOF1 phases in the amount of $\mathrm{STT}_{500}$, which is also accurately forecasted, with the negative EOF phase exhibiting peak values in the 0.75-1.25 SD range vs. $0.25-0.5 \mathrm{SDs}$ for the positive EOF phase. This asymmetry is likewise reflected in the forecast and verification PDFs of $\mathrm{STT}_{500}$ for the North Pacific subregion (Fig. 10a), where the median for the positive EOF1 


\section{EOF1-based TME}

(a) Verification positive phase

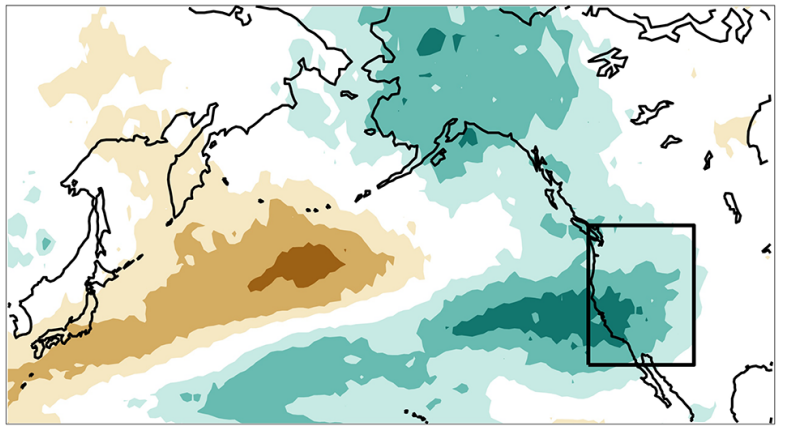

(c) Forecast positive phase (0.57)

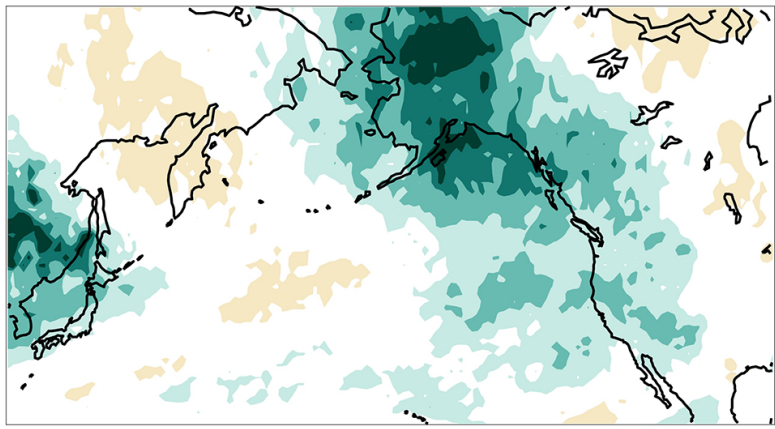

$130^{\circ} \mathrm{E} \quad 150^{\circ} \mathrm{E} \quad 170^{\circ} \mathrm{E} \quad 190^{\circ} \mathrm{E} \quad 210^{\circ} \mathrm{E} \quad 230^{\circ} \mathrm{E} \quad 250^{\circ} \mathrm{E} \quad 270^{\circ} \mathrm{E}$ (b) Verification negative phase

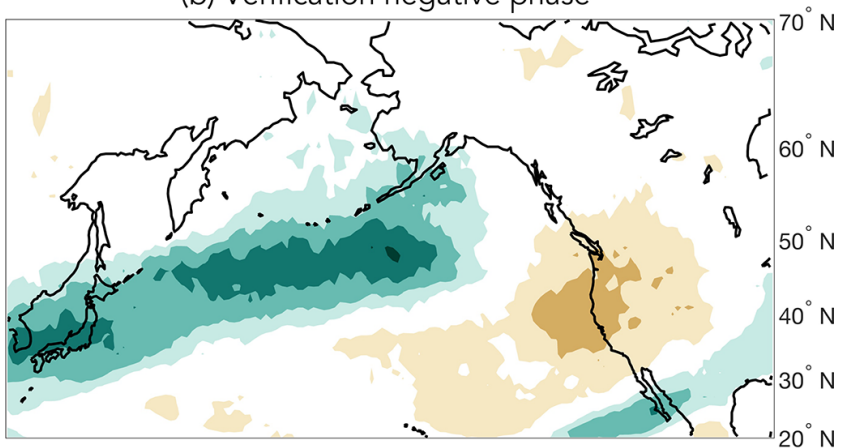

(d) Forecast negative phase (0.7)

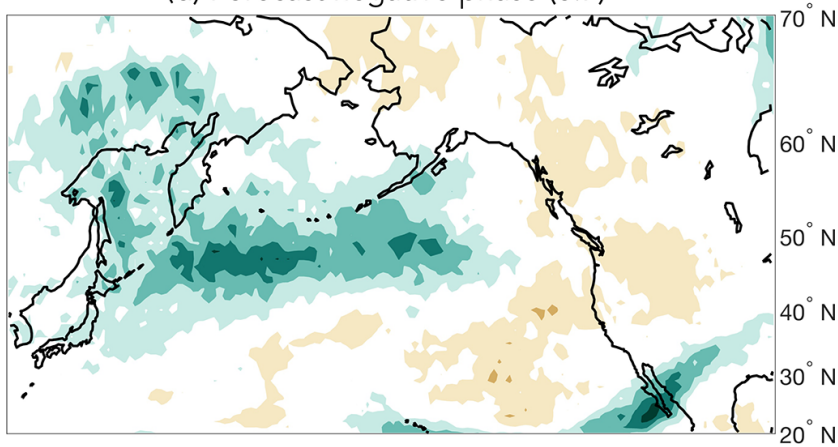

$130^{\circ} \mathrm{E} \quad 150^{\circ} \mathrm{E} \quad 170^{\circ} \mathrm{E} \quad 190^{\circ} \mathrm{E} \quad 210^{\circ} \mathrm{E} \quad 230^{\circ} \mathrm{E} \quad 250^{\circ} \mathrm{E} \quad 270^{\circ} \mathrm{E}$

Figure 8. (a, b) EOF1-based composites of TME for weeks 3-5 forecast periods when the verification time series (black line in Fig. 4) was above (positive phase) or below (negative phase) the $0.8 \mathrm{SD}$ threshold. (c, d) EOF1-based composites of TME for weeks 3-5 forecast periods when the forecast time series (orange line in Fig. 4) was above (positive phase) or below (negative phase) the 0.8 SD threshold. The black box outlines the western US subregion used for creating the transport PDF in Fig. 10c. Units are in SDs, and pattern correlations between top and bottom panels (cf., a vs. $\mathbf{c}$ and $\mathbf{b}$ vs. d) are shown in the bottom row titles.

phase is weakly negative, while the negative EOF1 phase has a greater than $+0.5 \mathrm{SD}$ median anomaly. The only noteworthy difference between the North Pacific forecast and verification PDFs is that the forecast-based PDF is shifted towards more positive values than the verification-based PDF. Regardless, the confidence intervals for the medians of the positive vs. negative phases of the forecast-based PDFs are very well-separated, and the underlying distributions are different according to a KS-test, which suggests that the predicted shifts in transport are significant. We also evaluated forecasts of $\mathrm{STT}_{500}$ for various subregions over populated land masses (e.g., the western United States), but the resulting verification and forecast PDFs were not significantly different, which reflects the fact that $\mathrm{STT}_{500}$ peaks over the North Pacific portion of the storm track (Fig. 3a).

For EOF2-based STTPBL over the western United States, the verification composite is consistent with the retrospective composites (cf., Figs. 7a and b vs. 3e); however, the pattern is much weaker. Nevertheless, the forecast- and verificationbased STT $_{\mathrm{PBL}}$ composites (Fig. 7c and d) and PDFs for the western US subregion (Fig. 10b) do agree quite well. However, the STT $_{\mathrm{PBL}}$ distribution is notably shifted away from zero only for the negative EOF phase and the confidence intervals for the medians overlap, which suggests that the STT $_{\text {PBL forecasts are probably borderline in their usefulness }}$ for most forecast periods. Still, the forecasted STT $\mathrm{PBL}_{\mathrm{P}}$ do represent different distributions according to a KS-test, so the change in the shape of the tails of the distributions may be of some practical use for the prediction of extreme STT $\mathrm{PBL}_{\mathrm{P}}$ events.

There are several potential reasons why the $\mathrm{STT}_{500}$ forecast and retrospective composite pattern amplitudes compare quite well (c.f. Figs. 3a and 6), while the STT ${ }_{\mathrm{PBL}}$ forecast and verification patterns are weaker than their retrospective counterparts (c.f. Figs. 3e and 7). First, STT $\mathrm{PBL}$ over the PacificNorth American region tends to be largest for two circumstances: regions with high orography and time periods when the PBL height is particularly high. These two circumstances coincide over the western to intermountain-western United States (Škerlak et al., 2014; Breeden et al., 2021) during 
(a) Verification positive phase

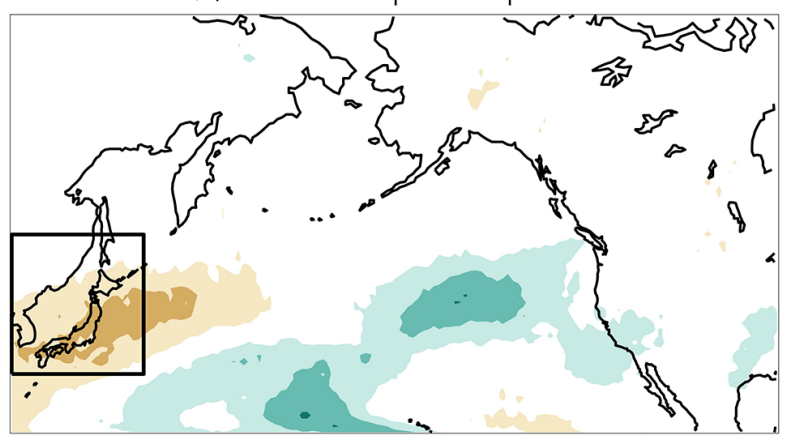

(c) Forecast positive phase (0.82)

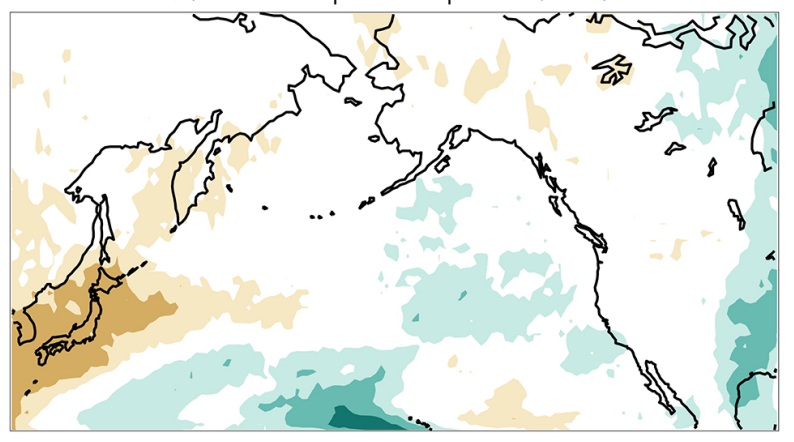

$130^{\circ} \mathrm{E} \quad 150^{\circ} \mathrm{E} \quad 170^{\circ} \mathrm{E} \quad 190^{\circ} \mathrm{E} \quad 210^{\circ} \mathrm{E} \quad 230^{\circ} \mathrm{E} \quad 250^{\circ} \mathrm{E} \quad 270^{\circ} \mathrm{E}$

\section{EOF2-based TME}

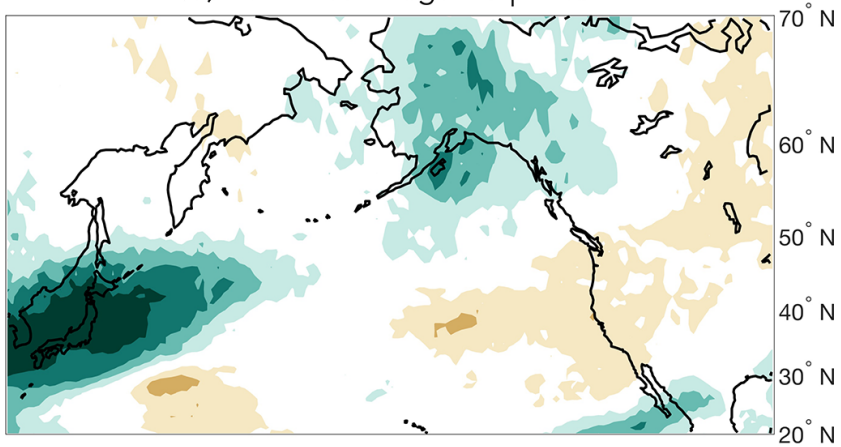

(d) Forecast negative phase (0.88)

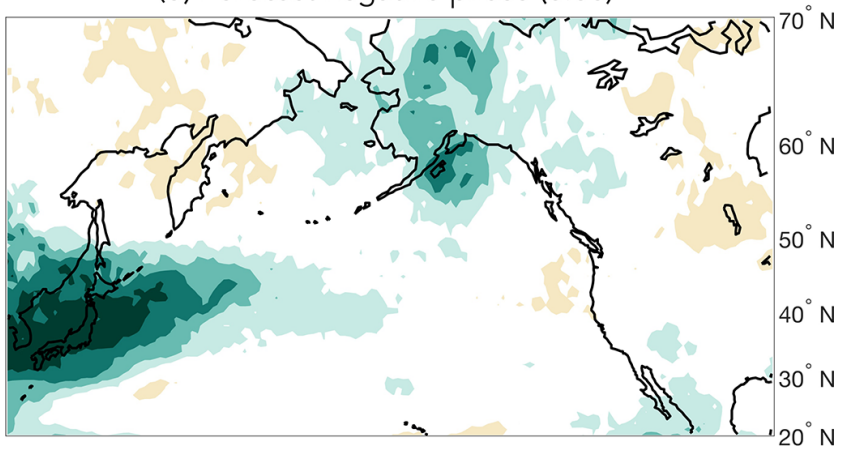

$130^{\circ} \mathrm{E} \quad 150^{\circ} \mathrm{E} \quad 170^{\circ} \mathrm{E} \quad 190^{\circ} \mathrm{E} \quad 210^{\circ} \mathrm{E} \quad 230^{\circ} \mathrm{E} \quad 250^{\circ} \mathrm{E} \quad 270^{\circ} \mathrm{E}$

$-1$

$-0.5$

0

0.5

1

Figure 9. (a, b) EOF2-based composites of TME for weeks 3-5 forecast periods when the verification time series (black line in Fig. 4) was above (positive phase) or below (negative phase) the $0.8 \mathrm{SD}$ threshold. (c, d) EOF2-based composites of TME for weeks 3-5 forecast periods when the forecast time series (orange line in Fig. 4) was above (positive phase) or below (negative phase) the 0.8 SD threshold. The black box outlines the West Pacific subregion used for creating the transport PDF in Fig. 10d. Units are in SDs, and pattern correlations between top and bottom panels (cf., a vs. $\mathbf{c}$ and $\mathbf{b}$ vs. d) are shown in the bottom row titles.

MAM, which coincides with the box area (Fig. 7a) used for our STT $_{\text {PBL }}$ PDF calculations (Fig. 10b). Unfortunately, PBL heights do not get particularly high until middle to late spring (see Fig. 5c of Breeden et al., 2021), which is the time period when Pacific jet forecasts are the least skillful (Fig. 5b). A second potential issue is that only a small percentage of overall STT events are deep enough to reach the lowermost troposphere (e.g., Škerlak et al., 2014, find that $36 \%$ of STT events reach $500 \mathrm{hPa}$, while only $5 \%$ reach $800 \mathrm{hPa}$; see their Fig. 4), which may magnify sampling issues related to the much smaller hindcast period (1997-2016) compared to the longer period (1979-2016) used for the retrospective analysis. We attempted to address the sampling issue by expanding the forecast averaging window from 3 weeks to 4 weeks; however, using an expanded 4 week averaging window yielded fewer well-forecasted periods, which also resulted in a weaker STT $_{\text {PBL }}$ pattern.

The TME forecasts match the verifications very well, both for EOFs and for both phases of each EOF, with basin-wide pattern correlations ranging from 0.57 to 0.88 (Figs. 8 and
9). In addition, the magnitude of the anomaly values for both EOFs are notable, with both TME phases exhibiting anomalies in the $0.5-1.25 \mathrm{SD}$ range over relatively large portions of the Pacific domain. Interestingly, positive TMEs centered over Alaska are predicted very well for the positive phase of EOF1 (Fig. 8a and c) and the negative phase of EOF2 (Fig. 9b and d), yet it is unclear if this pattern represents a reliably predictable form of TME because neither of the corresponding TME composites for the longer time record retrospective analysis show anomalies over Alaska (cf., Figs. 8 and 9 to $3 \mathrm{~g}$ and $\mathrm{h}$, respectively). In contrast, the forecasted patterns of TME between Japan and the west coast of the United States (south of $55^{\circ} \mathrm{N}$ ) are quite consistent with the jet (Figs. 1 and S1) and TME (Fig. 3, bottom row) patterns from the retrospective analysis, which suggests that TME over broad regions of the Pacific basin may be reasonably predictable during spring. Indeed, the western United States and West Pacific subregion TME PDF shifts are robust and match the verification PDFs very well (Fig. 10c and d, respectively). This is particularly true for the West Pacific where the me- 
(a) N. Pacific STT to 500 (EOF 1)

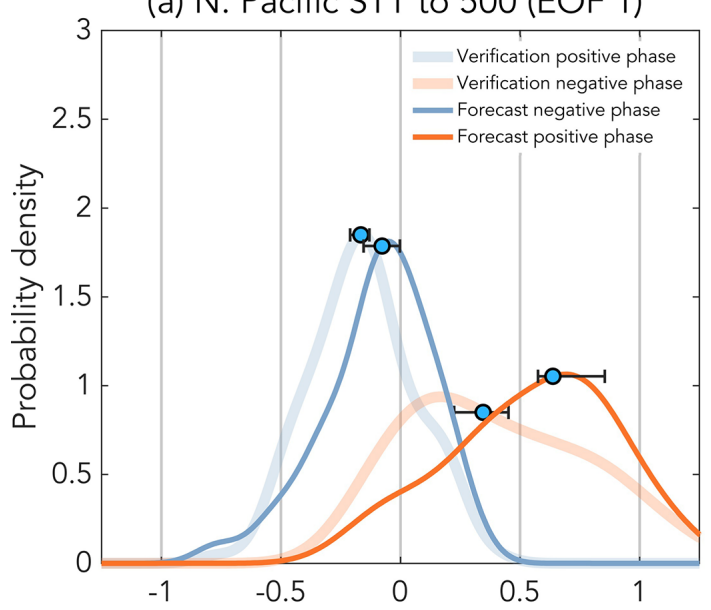

(c) US West Coast TME (EOF 1)

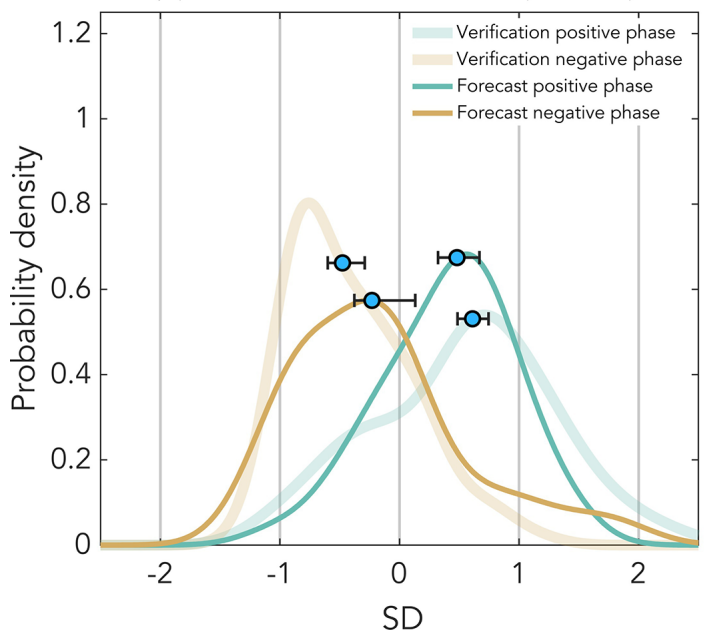

(b) Western CONUS STT to PBL (EOF 2)

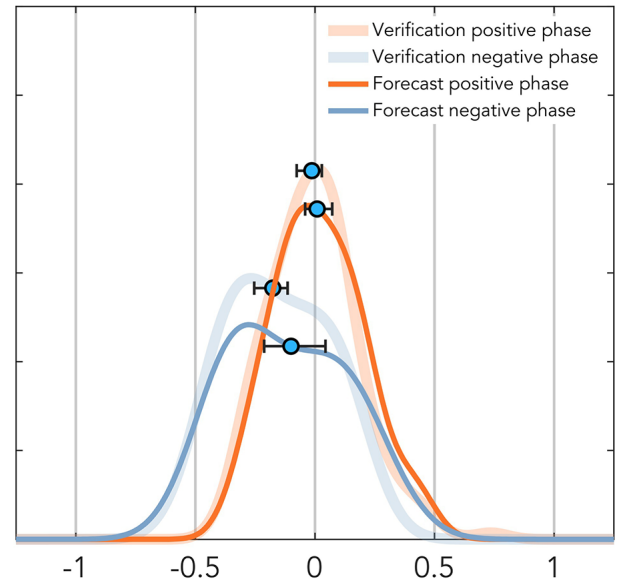

(d) W. Pacific TME (EOF 2)

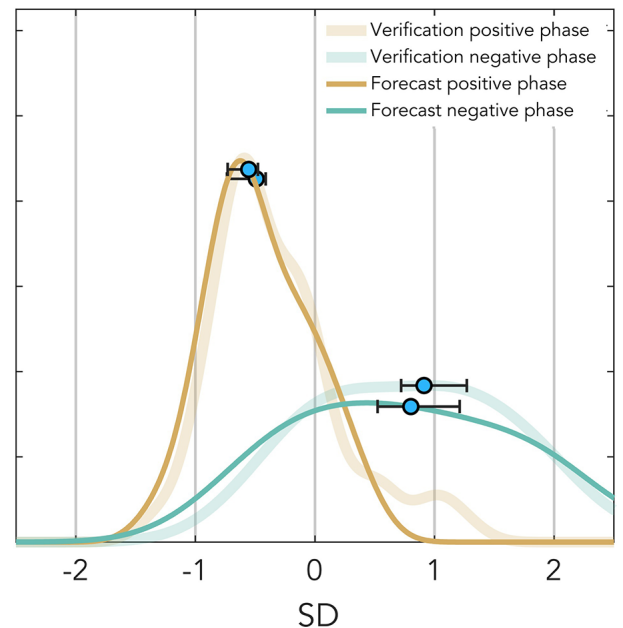

Figure 10. Probability density functions (PDFs) of (a) EOF1-based STT to $500 \mathrm{hPa}$ for the North Pacific subregion, (b) EOF2-based STT to the PBL for the western to intermountain-western US subregion, (c) EOF1-based TME to the western US subregion, and (d) EOF2-based TME to the West Pacific subregion. IFS-based forecasts are shown in solid dark lines, and ERA-Interim-based verifications are shown as thicker light lines; for both forecasts and verifications, medians are shown as blue dots, and 95th percentile bootstrap confidence intervals are shown as whiskers. Units are in SDs.

dian shift in TME transport is nearly \pm 1 SD for each EOF phase, and the PDF forecast and verification PDFs are nearly identical.

\section{Discussion and conclusions}

Many "modes" of climate variability are known to be associated with anomalous atmospheric transport. For example, stratosphere-to-troposphere mass and ozone transport to the PBL over North America is known to be influenced by ENSO (Breeden et al., 2021; Lin et al., 2015, and references therein), while the frequency of atmospheric rivers is thought to be modulated by a variety of climate phenomena, including ENSO, the Madden-Julian oscillation, and the quasibiennial oscillation (Guan et al., 2012; Lee et al., 2014; Kim and Alexander, 2015; Guan and Waliser, 2015; Mundhenk et al., 2016; Guirguis et al., 2019). However, retrospectively isolating such associations, which is equivalent to conducting a "perfect model" forecast, does not assure that current operational forecast models can successfully predict those relationships, particularly on subseasonal timescales (e.g., Lavers et al., 2016; Baggett et al., 2017). Nevertheless, some teleconnection and transport patterns appear to be potentially predictable on subseasonal timescales (e.g., Mundhenk et al., 2018; Wang and Robertson, 2019; Pan et al., 2019; DeFlorio et al., 2019; Yamagami and Matsueda, 2020), though these forecasts are typically found to occur during boreal winter.

Our analyses have shown that stratosphere-to-troposphere transport (STT) to at least $500 \mathrm{hPa}$ and long-range tropicalto-extratropical moisture export (TME) over the PacificNorth American region can potentially be skillfully predicted 
(a) El Niño

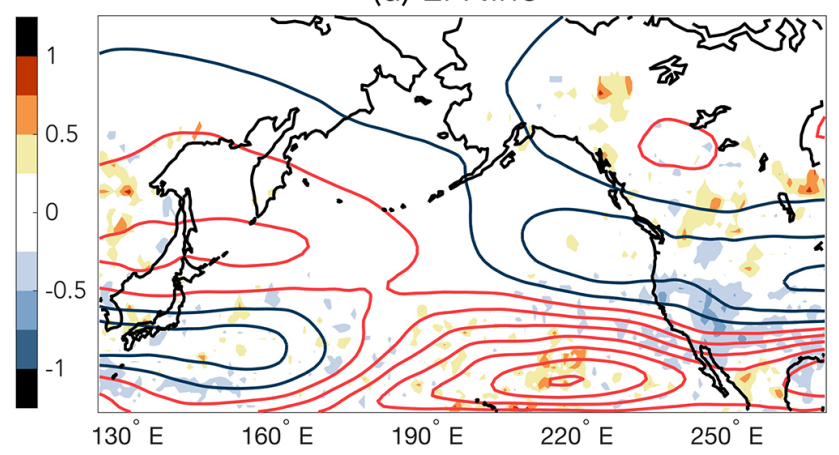

(c) STT to PBL probability - ENSO vs EOF2

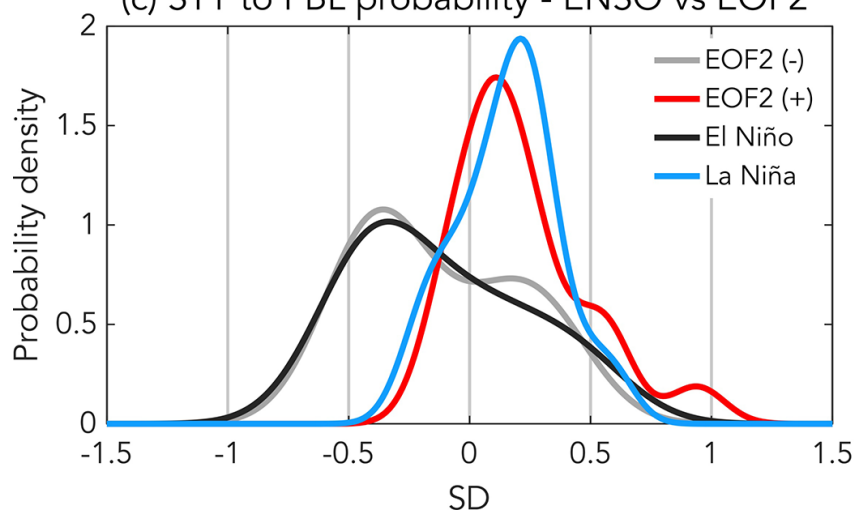

(b) La Niña

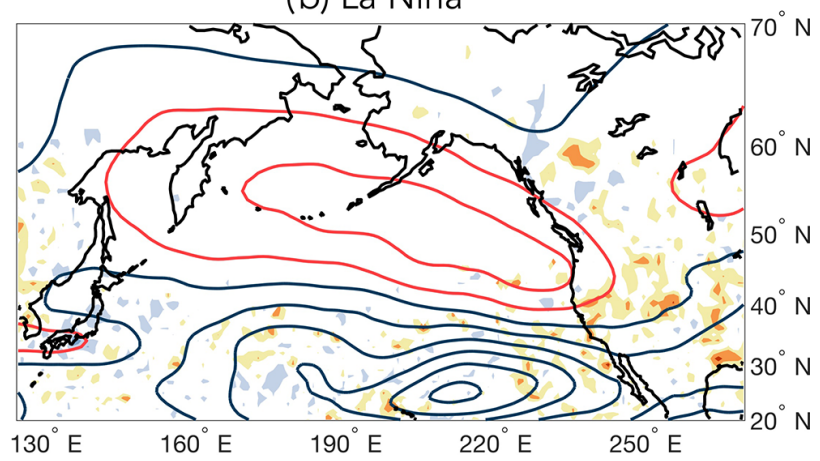

(d) ENSO - EOF2 [Correlation $=-0.78]$

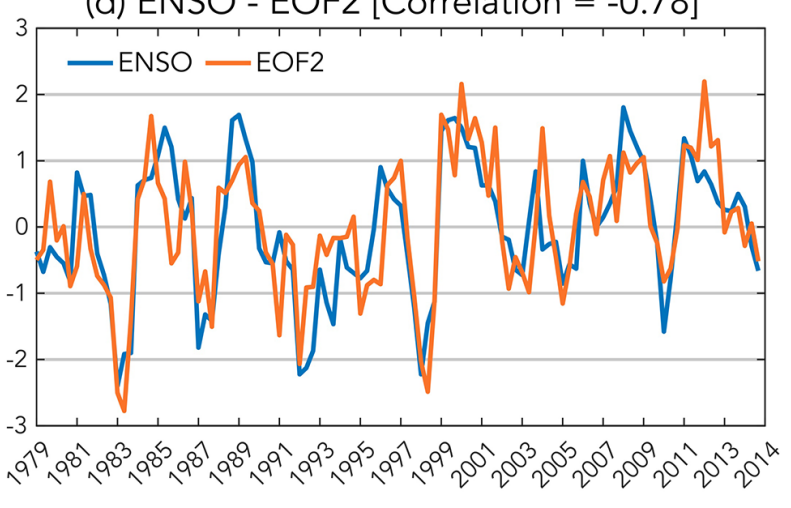

Figure 11. (a) El-Niño- and (b) La-Niña-based monthly mean (MAM, 1979-2014) frequencies of STT to the PBL (filled contours) and zonal winds (contours) for time periods when the NOAA ONI was \pm 0.8 SDs from climatology (units of SDs). Note: for correct comparison, panel (a) here should be compared to (d) from Fig. 4; compare also panels (a) and (b) here to panels (d) and (c) from Fig. S3. (c) Probability density functions (PDFs) of EOF2-based STT to the PBL for the western to intermountain-western US subregion. (d) Time series of the NOAA ONI (blue line) and PC2 (orange line), for which ONI has been multiplied by -1 for ease of comparison.

on subseasonal timescales (3-5 weeks ahead of time) during boreal spring. The transport forecasts themselves were inferred from ECMWF-IFS-based forecasts of Pacific jet variability. IFS Pacific jet forecasts for four Pacific-North American subregions are associated with significant shifts in the probability of anomalous transport, including the following: STT into the free troposphere over the North Pacific (Fig. 10a); STT into the planetary boundary layer over the intermountain-western United States (Fig. 10b); TME over the west coast of the United States (Fig. 10c); and TME to Japan and far eastern Asia (Fig. 10d). While the forecasted shifts in transport probability match verifications quite well, one deficiency is apparent: the IFS is able to predict the sign of the zonal wind PC time series with reasonable success (Table 2 and Fig. 4), yet it consistently struggles to maintain enough zonal-wind PC amplitude relative to the substantial weather-related noise (compare amplitude of forecast and verification time series in Fig. 4). This results in an underestimation of the number of anomalous transport days compared to observations (Fig. 5), which degrades the estimation of the transport probabilities (Fig. 10).
The underestimation of the number of anomalous transport days exhibits a strong seasonal dependence, which becomes quite acute during April and May (Fig. 5). This implies that either overall teleconnection predictability decreases as spring proceeds, or alternatively, the IFS is simply unable to skillfully predict large amplitude jet anomalies with consistency beyond early spring. While it is beyond the scope of the current study to explore which one of these possibilities is responsible for the lack of consistent late spring skill, this is clearly an important question because the first possibility would be a fundamental feature of the climate system, while the latter would be a model-based constraint that might theoretically be improved. Of course, these two possibilities are not mutually exclusive because the increasing sensitivity of Pacific-North American teleconnections to tropical forcing at smaller spatial scales during the spring jet transition (Newman and Sardeshmukh, 1998) may be inherently less predictable yet also more difficult to accurately model. That said, despite the IFS underestimation of the number of days with anomalously strong jet patterns (Fig. 5), the IFS is still able to identify roughly $15 \%$ (PC1) and $30 \%$ (PC2) of all spring days (March-May) that are anomalous, which sug- 
gests that using upper-level winds to forecast transport may currently be possible.

For the three types of transport that we have evaluated here, STT into the free troposphere and TME are the most robustly predicted, at least in terms of shifts of the average and extremes of their transport distributions (Fig. 10). STT to the PBL over the western United States, on the other hand, mainly exhibits a change in the shape of the tails of the transport distributions but a rather weak shift in the median (i.e., the shifts of the medians of the two EOF2 phases have confidence intervals that are strongly overlapping; Fig. 10b). This has implications for the suggestion that ENSO may be used to predict air quality related to STT of ozone during spring (e.g., Lin et al., 2015 and Albers et al., 2018, and references therein). Similar to previous retrospective analyses (e.g., Lin et al., 2015; Breeden et al., 2021), we find that mass transport to the PBL is associated with ENSO (Fig. 11), where here, we have composited $\mathrm{STT}_{\mathrm{PBL}}$ based on periods when the NOAA ONI is greater than $0.8 \mathrm{SDs}$ from the historical mean, which yields an equivalent number of samples to our EOF2-based results. The ONI-based (retrospective) transport composites look very similar to our earlier EOF2-based retrospective results (cf., Figs. 11a and b to $3 \mathrm{e}$ and S3c, respectively. For a proper comparison, note that $\mathrm{PC} 2$ and ONI are negatively correlated). Moreover, the transport PDFs for the intermountain-western US subregion based on PC2 vs. ONI, for both ENSO phases, are drawn from the same distributions according to a two-sample Kolmogorov-Smirnov test (Fig. 11c). This close correspondence is due to the high correlation between the ONI and PC2 time series (Fig. 11d). Yet, because we have found $\mathrm{STT}_{\mathrm{PBL}}$ predictions related to EOF2 to be significant only in terms of shifts in the tails of the distributions (cf. Figs. 10b and 11c), our results suggest that at best, ENSO may be harnessed to provide $\mathrm{STT}_{\mathrm{PBL}}$ forecast guidance on subseasonal timescales for extreme events only. Complicating matters further in the context of ozone transport to the PBL (as opposed to simply mass transport as investigated here) is that predictions based on ENSO will likely be even more difficult because the STT of ozone is also modulated by the seasonal variability in the available reservoir of ozone in the extratropical lower stratosphere (Olsen et al., 2013; Neu et al., 2014; Albers et al., 2018). That said, because it is doubtful that Niño-3.4-based indices like ONI capture the full dynamical scope of ENSO variability (Penland and Matrosova, 2006; Capotondi et al., 2015), the complete impact of ENSO on STTPBL predictability certainly deserves further study. 


\section{Appendix A}

To verify that EOFs $1-3$ represent distinct patterns that are robust to variations in sampling period (North et al., 1982), we conducted several calculations. To begin, a $10000 \mathrm{mem}-$ ber bootstrap ensemble of $200 \mathrm{hPa}$ zonal wind EOFs was created (resampling with replacement), in which each bootstrap member consisted of " $N$ " randomly selected monthly mean $200 \mathrm{hPa}$ zonal wind anomalies for the Pacific basin domain shown in Fig. 2. The $N$ randomly selected anomalies are chosen from the pool of all MAM 1979-2016 monthly means, and $N=114$, which is the number of months in the original EOF calculation for MAM, 1979-2016. The resulting data were used in three calculations.

First, the pattern correlation between each bootstrap ensemble member EOF and the corresponding original EOF was calculated. The median pattern correlation for all 10000 bootstrap ensemble members was then calculated. For all three EOFs, the median pattern correlation was near 0.9 (individual values are shown for each of the three EOFs in the title bars of Fig. A1a-f). Next, the median of the variance explained was calculated for each bootstrap ensemble EOF. For all three EOFs, the variance explained for the original EOFs and for the median of the bootstrap ensemble EOFs is within a couple percent (individual values are shown for each of the EOFs in the title bars of Fig. A1a-f). Finally, the standard deviation of the variance explained was calculated for each of the bootstrap ensembles (Fig. A1g). The spread (measured by the standard deviation) is small enough that there is no overlap between each of the first three EOFs. In combination, these calculations support the notion that the first three $200 \mathrm{hPa}$ zonal wind EOFs are not degenerate according to the criteria outlined in North et al. (1982).
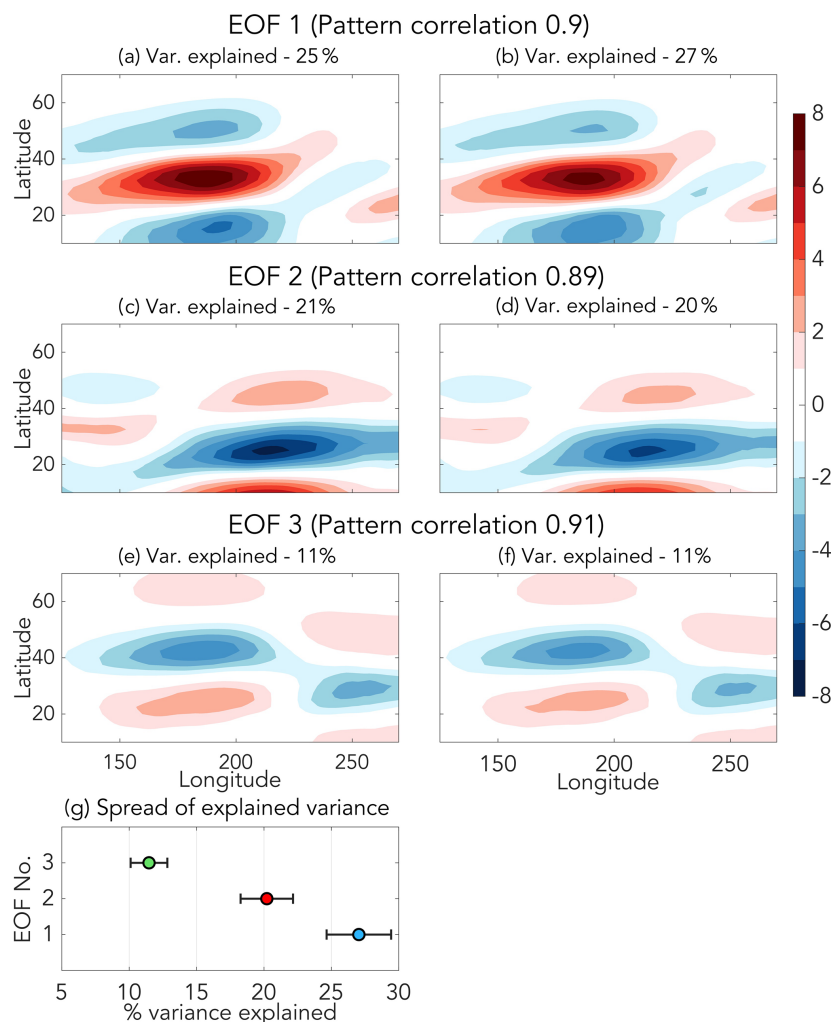

Figure A1. (a, c, e) $200 \mathrm{hPa}$ zonal wind EOF patterns for MAM, 1979-2016, which correspond to the EOF contours shown in Figs. 2-3 and S1-S4. (b, d, f) $200 \mathrm{hPa}$ zonal wind EOF patterns for the bootstrap ensembles corresponding to panels $(\mathbf{a}, \mathbf{c}, \mathbf{e})$, respectively. For each row in (a-f), the median pattern correlation between the original (left column) and bootstrap ensembles (right column) are shown in the subtitle. The subtitle of each panel in (af) also shows the variance explained (original EOFs, left column) or the median variance explained (bootstrap ensembles, right column) for each EOF. (g) Median variance explained for the bootstrap ensemble (solid marker) and the spread of variance explained for the bootstrap ensembles of each EOF, in which the spread is calculated as $1 \mathrm{SD}$ of the variance explained (shown as whiskers). 
Data availability. The ERA-Interim reanalysis data used in this study are available through the National Center for Atmospheric Research Consortium for Atmospheric Research Data Archive: https://doi.org/10.5065/D6HH6H41 (Research Data Archive at the National Center for Atmospheric Research, 2013). The STT, TME, and jet ERA-Interim feature-based climatology data are available from http://eraiclim.ethz.ch/ (ETH Zürich, 2020). ECMWF IFS hindcast data are available via the S2S Prediction Project (http: //s2sprediction.net/, Vitart et al., 2017).

Supplement. The supplement related to this article is available online at: https://doi.org/10.5194/wcd-2-433-2021-supplement.

Author contributions. JRA wrote retrospective and hindcast analysis code, created the figures, and wrote the manuscript. AHB, MLB, AOL, and GNK provided comments and edited the manuscript.

Competing interests. The authors declare that they have no conflict of interest.

Acknowledgements. The authors would like to thank Michael Sprenger for graciously making the 6-hourly ETH-Zürich feature-based data available, which made this study possible. The authors also wish to thank two anonymous reviewers whose comments improved the science and clarity of the manuscript. The authors would like to thank Yan Wang for preparing the IFS S2S data and Benjamin Moore, who helped furnish the 6-hourly TME data.

Financial support. John R. Albers and Amy H. Butler were funded in part by NSF grant \#1756958. Melissa L. Breeden was funded by the NOAA Climate and Global Change Postdoctoral Fellowship Program, administered by UCAR's Cooperative Programs for the Advancement of Earth System Science (CPAESS) under award \# NA18NWS4620043B.

Review statement. This paper was edited by Christian M. Grams and reviewed by two anonymous referees.

\section{References}

Abatzoglou, J. T. and Magnusdottir, G.: Planetary wave breaking and nonlinear reflection: Seasonal cycle and interannual variability, J. Climate, 19, 6139-6152, 2006.

Albers, J. R. and Newman, M.: A priori identification of skillful extratropical subseasonal forecasts, Geophys. Res. Lett., 46, 12527-12536, 2019

Albers, J. R., Perlwitz, J., Butler, A. H., Birner, T., Kiladis, G. N., Lawrence, Z. D., Manney, G. L., Langford, A. O., and Dias, J.: Mechanisms governing interannual variability of stratosphere- to-troposphere ozone transport, J. Geophys. Res., 123, 234-260, 2018.

Appenzeller, C., Davies, H., and Norton, W.: Fragmentation of stratospheric intrusions, J. Geophys. Res., 101, 1435-1456, 1996.

Arpe, K., Hollingsworth, A., Tracton, M., Lorenc, A., Uppala, S., and Kållberg, P.: The response of numerical weather prediction systems to FGGE level IIb data. Part II: Forecast verifications and implications for predictability, Q. J. Roy. Meteor. Soc., 111, 67-101, 1985.

Baggett, C. F., Barnes, E. A., Maloney, E. D., and Mundhenk, B. D.: Advancing atmospheric river forecasts into subseasonal-toseasonal time scales, Geophys. Res. Lett., 44, 7528-7536, 2017.

Bao, J., Michelson, S., Neiman, P., Ralph, F., and Wilczak, J.: Interpretation of enhanced integrated water vapor bands associated with extratropical cyclones: Their formation and connection to tropical moisture, Mon. Weather Rev., 134, 1063-1080, 2006.

Barnston, A. G.: Linear statistical short-term climate predictive skill in the Northern Hemisphere, J. Climate, 7, 1513-1564, 1994.

Barsugli, J. J. and Sardeshmukh, P. D.: Global atmospheric sensitivity to tropical SST anomalies throughout the Indo-Pacific basin, J. Climate, 15, 3427-3442, 2002.

Branković, $\hat{\mathrm{C}}$. and Palmer, T.: Atmospheric seasonal predictability and estimates of ensemble size, Mon. Weather Rev., 125, 859874, 1997.

Breeden, M. L., Butler, A. H., Albers, J. R., Sprenger, M., and Langford, A. O.: The spring transition of the North Pacific jet and its relation to deep stratosphere-to-troposphere mass transport over western North America, Atmos. Chem. Phys., 21, 2781-2794, https://doi.org/10.5194/acp-21-2781-2021, 2021.

Buizza, R. and Leutbecher, M.: The forecast skill horizon, Q. J. Roy. Meteor. Soc., 141, 3366-3382, 2015.

Capotondi, A., Wittenberg, A. T., Newman, M., Di Lorenzo, E., Yu, J.-Y., Braconnot, P., Cole, J., Dewitte, B., Giese, B., Guilyardi, E., Jin, F.-F., Karnauskas, K., Kirtman, B., Lee, T., Schneider, N., Xue, Y., and Yeh, S.-W.: Understanding ENSO diversity, B. Am. Meteorol. Soc., 96, 921-938, 2015.

Cayan, D. R. and Roads, J. O.: Local relationships between United States West Coast precipitation and monthly mean circulation parameters, Mon. Weather Rev., 112, 1276-1282, 1984.

Compo, G. P. and Sardeshmukh, P. D.: Storm track predictability on seasonal and decadal scales, J. Climate, 17, 3701-3720, 2004.

Cooper, O. R., Langford, A. O., Parrish, D. D., and Fahey, D. W.: Challenges of a lowered US ozone standard, Science, 348, 10961097, 2015.

Dee, D. P., Uppala, S. M., Simmons, A. J., Berrisford, P., Poli, P., Kobayashi, S., Andrae, U., Balmaseda, M. A., Balsamo, G., Bauer, P., Bechtold, P., Beljaars, A. C. M., van de Berg, L., Bidlot, J., Bormann, N., Delsol, C., Dragani, R., Fuentes, M., Geer, A. J., Haimberger, L., Healy, S. B., Hersbach, H., Hólm, E. V., Isaksen, L., Kållberg, P., Köhler, M., Matricardi, M., McNally, A. P., Monge-Sanz, B. M., Morcrette, J.-J., Park, B.-K., Peubey, C., de Rosnay, P., Tavolato, C., Thépaut, J.-N., and Vitart, F.: The ERA-Interim reanalysis: Configuration and performance of the data assimilation system, Q. J. Roy. Meteor. Soc., 137, 553-597, 2011.

DeFlorio, M. J., Waliser, D. E., Guan, B., Lavers, D. A., Ralph, F. M., and Vitart, F.: Global assessment of atmospheric river prediction skill, J. Hydrometeorol., 19, 409-426, 2018. 
DeFlorio, M. J., Waliser, D. E., Guan, B., Ralph, F. M., and Vitart, F.: Global evaluation of atmospheric river subseasonal prediction skill, Clim. Dynam., 52, 3039-3060, 2019.

ETH Zürich: Feature-based ERA-Interim Climatologies, available at: available at: http://eraiclim.ethz.ch/, last access: January 2020.

Feldstein, S. B.: The timescale, power spectra, and climate noise properties of teleconnection patterns, J. Climate, 13, 4430-4440, 2000.

Fiore, A., Jacob, D. J., Liu, H., Yantosca, R. M., Fairlie, T. D., and $\mathrm{Li}, \mathrm{Q}$.: Variability in surface ozone background over the United States: Implications for air quality policy, J. Geophys. Res., 108, 4787, https://doi.org/10.1029/2003JD003855, 2003.

Fiore, A., Oberman, J., Lin, M., Zhang, L., Clifton, O., Jacob, D. J., Naik, V., Horowitz, L., Pinto, J., and Milly, G.: Estimating North American background ozone in US surface air with two independent global models: Variability, uncertainties, and recommendations, Atmos. Environ., 96, 284-300, 2014.

Gershunov, A., Shulgina, T., Ralph, F. M., Lavers, D. A., and Rutz, J. J.: Assessing the climate-scale variability of atmospheric rivers affecting western North America, Geophys. Res. Lett., 44, 7900-7908, 2017.

Guan, B. and Waliser, D. E.: Detection of atmospheric rivers: Evaluation and application of an algorithm for global studies, J. Geophys. Res., 120, 12514-12535, 2015.

Guan, B., Waliser, D. E., Molotch, N. P., Fetzer, E. J., and Neiman, P. J.: Does the Madden-Julian oscillation influence wintertime atmospheric rivers and snowpack in the Sierra Nevada?, Mon. Weather Rev., 140, 325-342, 2012.

Guirguis, K., Gershunov, A., Shulgina, T., Clemesha, R. E., and Ralph, F. M.: Atmospheric rivers impacting Northern California and their modulation by a variable climate, Clim. Dynam., 52, 6569-6583, 2019.

Higgins, R., Schemm, J. E., Shi, W., and Leetmaa, A.: Extreme precipitation events in the western United States related to tropical forcing, J. Climate, 13, 793-820, 2000.

Hitchman, M. H. and Huesmann, A. S.: A seasonal climatology of Rossby wave breaking in the 320-2000-K layer, J. Atmos. Sci., 64, 1922-1940, 2007.

Hoerling, M. P., Schaack, T. K., and Lenzen, A. J.: A global analysis of stratospheric-tropospheric exchange during northern winter, Mon. Weather Rev., 121, 162-172, 1993.

Hollander, M., Wolfe, D. A., and Chicken, E.: Nonparametric statistical methods, Vol. 751, John Wiley and Sons, Hoboken, New Jersey, USA, 2013.

Hollingsworth, A., Arpe, K., Tiedtke, M., Capaldo, M., and Savijärvi, H.: The performance of a medium-range forecast model in winter impact of physical parameterizations, Mon. Weather Rev., 108, 1736-1773, 1980.

Hoskins, B. and Hodges, K.: The annual cycle of Northern Hemisphere storm tracks. Part I: Seasons, J. Climate, 32, 1743-1760, 2019.

Hoskins, B. J. and Ambrizzi, T.: Rossby wave propagation on a realistic longitudinally varying flow, J. Atmos. Sci., 50, 1661-1671, 1993.

Johansson, Å.: Prediction skill of the NAO and PNA from daily to seasonal time scales, J. Climate, 20, 1957-1975, 2007.
Kim, H.-M. and Alexander, M. A.: ENSO's modulation of water vapor transport over the Pacific-North American region, J. Climate, 28, 3846-3856, 2015.

Knippertz, P. and Martin, J. E.: A Pacific moisture conveyor belt and its relationship to a significant precipitation event in the semiarid southwestern United States, Weather Forecast., 22, 125-144, 2007.

Knippertz, P. and Wernli, H.: A Lagrangian climatology of tropical moisture exports to the Northern Hemispheric extratropics, J. Climate, 23, 987-1003, 2010.

Knippertz, P., Wernli, H., and Gläser, G.: A global climatology of tropical moisture exports, J. Climate, 26, 3031-3045, 2013.

Koch, P., Wernli, H., and Davies, H. C.: An event-based jet-stream climatology and typology, Int. J. Climatol., 26, 283-301, 2006.

Langford, A.: Stratosphere-troposphere exchange at the subtropical jet: Contribution to the tropospheric ozone budget at midlatitudes, Geophys. Res. Lett., 26, 2449-2452, 1999.

Langford, A. and Reid, S.: Dissipation and mixing of a smallscale stratospheric intrusion in the upper troposphere, J. Geophys. Res., 103, 31265-31276, 1998.

Langford, A., O'Leary, T., Masters, C., Aikin, K., and Proffitt, M.: Modulation of middle and upper tropospheric ozone at northern midlatitudes by the El Niño/Southern Oscillation, Geophys. Res. Lett., 25, 2667-2670, 1998.

Langford, A., Aikin, K., Eubank, C., and Williams, E.: Stratospheric contribution to high surface ozone in Colorado during springtime, Geophys. Res. Lett., 36, L12801, https://doi.org/10.1029/2009GL038367, 2009.

Langford, A., Brioude, J., Cooper, O., Senff, C., Alvarez, R., Hardesty, R., Johnson, B., and Oltmans, S.: Stratospheric influence on surface ozone in the Los Angeles area during late spring and early summer of 2010, J. Geophys. Res., 117, D00V06, https://doi.org/10.1029/2011JD016766, 2012.

Lavers, D. A., Pappenberger, F., and Zsoter, E.: Extending mediumrange predictability of extreme hydrological events in Europe, Nat. Commun., 5, 1-7, 2014.

Lavers, D. A., Waliser, D. E., Ralph, F. M., and Dettinger, M. D.: Predictability of horizontal water vapor transport relative to precipitation: Enhancing situational awareness for forecasting western US extreme precipitation and flooding, Geophys. Res. Lett., 43, 2275-2282, 2016.

Lee, S.-K., Mapes, B. E., Wang, C., Enfield, D. B., and Weaver, S. J.: Springtime ENSO phase evolution and its relation to rainfall in the continental US, Geophys. Res. Lett., 41, 1673-1680, 2014.

Lefohn, A. S., Wernli, H., Shadwick, D., Limbach, S., Oltmans, S. J., and Shapiro, M.: The importance of stratospherictropospheric transport in affecting surface ozone concentrations in the western and northern tier of the United States, Atmos. Environ., 45, 4845-4857, 2011.

Lin, M., Fiore, A. M., Horowitz, L. W., Langford, A. O., Oltmans, S. J., Tarasick, D., and Rieder, H. E.: Climate variability modulates western US ozone air quality in spring via deep stratospheric intrusions, Nat. Commun., 6, 7105, https://doi.org/10.1038/ncomms8105, 2015.

Madonna, E., Wernli, H., Joos, H., and Martius, O.: Warm conveyor belts in the ERA-Interim dataset (1979-2010). Part I: Climatology and potential vorticity evolution, J. Climate, 27, 3-26, 2014. 
Mahoney, K., Jackson, D. L., Neiman, P., Hughes, M., Darby, L., Wick, G., White, A., Sukovich, E., and Cifelli, R.: Understanding the role of atmospheric rivers in heavy precipitation in the southeast United States, Mon. Weather Rev., 144, 1617-1632, 2016.

G. Marsaglia, Tsang, W. W., and Wang, J.: Evaluating Kolmogorov's distribution, J. Stat. Softw., 8, 1-4, 2003.

Monahan, A. H., Fyfe, J. C., Ambaum, M. H., Stephenson, D. B., and North, G. R.: Empirical orthogonal functions: The medium is the message, J. Climate, 22, 6501-6514, 2009.

Monhart, S., Spirig, C., Bhend, J., Bogner, K., Schär, C., and Liniger, M. A.: Skill of subseasonal forecasts in Europe: Effect of bias correction and downscaling using surface observations, J. Geophys. Res., 123, 7999-8016, 2018.

Mundhenk, B. D., Barnes, E. A., and Maloney, E. D.: All-season climatology and variability of atmospheric river frequencies over the North Pacific, J. Climate, 29, 4885-4903, 2016.

Mundhenk, B. D., Barnes, E. A., Maloney, E. D., and Baggett, C. F.: Skillful empirical subseasonal prediction of landfalling atmospheric river activity using the Madden-Julian oscillation and quasi-biennial oscillation, NPJ Climate and Atmospheric Science, 1, 1-7, 2018.

Murphy, A. H. and Epstein, E. S.: Skill scores and correlation coefficients in model verification, Mon. Weather Rev., 117, 572-582, 1989

Nakamura, H.: Midwinter suppression of baroclinic wave activity in the Pacific, J. Atmos. Sci., 49, 1629-1642, 1992.

Neu, J. L., Flury, T., Manney, G. L., Santee, M. L., Livesey, N. J., and Worden, J.: Tropospheric ozone variations governed by changes in stratospheric circulation, Nat. Geosci., 7, 340-344, 2014

Newman, M. and Sardeshmukh, P. D.: The impact of the annual cycle on the North Pacific/North American response to remote low-frequency forcing, J. Atmos. Sci., 55, 1336-1353, 1998.

Newman, M., Kiladis, G. N., Weickmann, K. M., Ralph, F. M., and Sardeshmukh, P. D.: Relative contributions of synoptic and lowfrequency eddies to time-mean atmospheric moisture transport, including the role of atmospheric rivers, J. Climate, 25, 73417361, 2012.

North, G. R., Bell, T. L., Cahalan, R. F., and Moeng, F. J.: Sampling errors in the estimation of empirical orthogonal functions, Mon. Weather Rev., 110, 699-706, 1982.

Olsen, M. A., Douglass, A. R., and Kaplan, T. B.: Variability of extratropical ozone stratosphere-troposphere exchange using microwave limb sounder observations, J. Geophys. Res., 118, 1090-1099, 2013.

Olsen, M. A., Manney, G. L., and Liu, J.: The ENSO and QBO Impact on Ozone Variability and Stratosphere-Troposphere Exchange Relative to the Subtropical Jets, J. Geophys. Res., 124, 7379-7392, 2019.

Pan, B., Hsu, K., AghaKouchak, A., Sorooshian, S., and Higgins, W.: Precipitation prediction skill for the West Coast United States: From short to extended range, J. Climate, 32, 161-182, 2019

Pavan, V., Tibaldi, S., and Branković, Ĉ.: Seasonal prediction of blocking frequency: Results from winter ensemble experiments, Q. J. Roy. Meteor. Soc., 126, 2125-2142, 2000.
Penland, C. and Matrosova, L.: Studies of El Nino and interdecadal variability in tropical sea surface temperatures using a nonnormal filter, J. Climate, 19, 5796-5815, 2006.

Pfahl, S., Madonna, E., Boettcher, M., Joos, H., and Wernli, H.: Warm conveyor belts in the ERA-Interim dataset (1979-2010). Part II: Moisture origin and relevance for precipitation, J. Climate, 27, 27-40, 2014.

Ralph, F. and Dettinger, M.: Storms, floods, and the science of atmospheric rivers, EOS T. Am. Geophys. Un., 92, 265-266, 2011.

Ralph, F. M., Dettinger, M. D., Cairns, M. M., Galarneau, T. J., and Eylander, J.: Defining "atmospheric river": How the Glossary of Meteorology helped resolve a debate, B. Am. Meteorol. Soc., 99, 837-839, 2018.

Reed, R. J. and Danielsen, E. F.: Fronts in the vicinity of the tropopause, Arch. Meteor. Geophy. A, 11, 1-17, 1958.

Research Data Archive at the National Center for Atmospheric Research: Computational and Information Systems Laboratory, https://doi.org/10.5065/D6HH6H41, 2013 (updated monthly).

Rivière, G.: Role of Rossby wave breaking in the west Pacific teleconnection, Geophys. Res. Lett., 37, L11802, https://doi.org/10.1029/2010GL043309, 2010.

Ryoo, J.-M., Kaspi, Y., Waugh, D. W., Kiladis, G. N., Waliser, D. E., Fetzer, E. J., and Kim, J.: Impact of Rossby wave breaking on US West Coast winter precipitation during ENSO events, J. Climate, 26, 6360-6382, 2013

Schwierz, C., Dirren, S., and Davies, H. C.: Forced waves on a zonally aligned jet stream, J. Atmos. Sci., 61, 73-87, 2004.

Scott, R. and Cammas, J.: Wave breaking and mixing at the subtropical tropopause, J. Atmos. Sci., 59, 2347-2361, 2002.

Seidel, D. J., Zhang, Y., Beljaars, A., Golaz, J.-C., Jacobson, A. R., and Medeiros, B.: Climatology of the planetary boundary layer over the continental United States and Europe, J. Geophys. Res., 117, D17106, https://doi.org/10.1029/2012JD018143, 2012.

Shapiro, M.: Turbulent mixing within tropopause folds as a mechanism for the exchange of chemical constituents between the stratosphere and troposphere, J. Atmos. Sci., 37, 994-1004, 1980.

Shapiro, M. A. and Keyser, D.: Fronts, jet streams and the tropopause, in: Extratropical Cyclones. The Erik Palmen Memorial Volume, American Meteorological Society, 167-191, 1990.

Škerlak, B., Sprenger, M., and Wernli, H.: A global climatology of stratosphere-troposphere exchange using the ERA-Interim data set from 1979 to 2011, Atmos. Chem. Phys., 14, 913-937, https://doi.org/10.5194/acp-14-913-2014, 2014.

Škerlak, B., Sprenger, M., Pfahl, S., Tyrlis, E., and Wernli, H.: Tropopause folds in ERA-Interim: Global climatology and relation to extreme weather events, J. Geophys. Res., 120, 4860 4877, 2015.

Sodemann, H., Wernli, H., Knippertz, P., Cordeira, J. M., Dominguez, F., Guan, B., Hu, H., Ralph, F. M., and Stohl, A.: Structure, process, and mechanism, in: Atmospheric Rivers, Springer, Cham, 15-43, https://doi.org/10.1007/978-3030-28906-5_2, 2020.

Sprenger, M. and Wernli, H.: The LAGRANTO Lagrangian analysis tool - version 2.0, Geosci. Model Dev., 8, 2569-2586, https://doi.org/10.5194/gmd-8-2569-2015, 2015.

Sprenger, M., Maspoli, M. C., and Wernli, H.: Tropopause folds and cross-tropopause exchange: A global investigation based upon ECMWF analyses for the time period 
March 2000 to February 2001, J. Geophys. Res., 108, 8518, https://doi.org/10.1029/2002JD002587, 2003.

Sprenger, M., Wernli, H., and Bourqui, M.: Stratospheretroposphere exchange and its relation to potential vorticity streamers and cutoffs near the extratropical tropopause, J. Atmos. Sci., 64, 1587-1602, 2007.

Sprenger, M., Fragkoulidis, G., Binder, H., Croci-Maspoli, M., Graf, P., Grams, C. M., Knippertz, P., Madonna, E., Schemm, S., Škerlak, B., and Wernli, H.: Global climatologies of Eulerian and Lagrangian flow features based on ERA-Interim, B. Am. Meteorol. Soc., 98, 1739-1748, 2017.

Stohl, A. and James, P.: A Lagrangian Analysis of the Atmospheric Branch of the Global Water Cycle. Part II: Moisture Transports between Earth's Ocean Basins and River Catchments, J. Hydrometeorol., 6, 961-984, 2005.

Straus, D. M. and Shukla, J.: Does ENSO force the PNA?, J. Climate, 15, 2340-2358, 2002.

Swain, D. L., Horton, D. E., Singh, D., and Diffenbaugh, N. S.: Trends in atmospheric patterns conducive to seasonal precipitation and temperature extremes in California, Sci. Adv., 2, e1501344, https://doi.org/10.1126/sciadv.1501344, 2016.

U.S. EPA: Air Quality Criteria For Ozone and Related Photochemical Oxidants (Final Report, 2006), U.S. Environmental Protection Agency, Washington, DC, EPA/600/R-05/004aF-cF, 2006.

Van Den Dool, H. M. and Toth, Z.: Why do forecasts for "near normal" often fail?, Weather Forecast., 6, 76-85, 1991.

Vitart, F., Ardilouze, C., Bonet, A., Brookshaw, A., Chen, M., Codorean, C., Déqué, M., Ferranti, L., Fucile, E., Fuentes, M., Hendon, H., Hodgson, J., Kang, H.-S., Kumar, A., Lin, H., Liu, G., Liu, X., Malguzzi, P., Mallas, I., Manoussakis, M., Mastrangelo, D., MacLachlan, C., McLean, P., Minami, A., Mladek, R., Nakazawa, T., Najm, S., Nie, Y., Rixen, M., Robertson, A. W., Ruti, P., Sun, C., Takaya, Y., Tolstykh, M., Venuti, F., Waliser, D., Woolnough, S., Wu, T., Won, D.-J., Xiao, H., Zaripov, R., and Zhang, L.: The subseasonal to seasonal (S2S) prediction project database, B. Am. Meteorol. Soc., 98, 163-173, 2017 (data available at: http://s2sprediction.net/, last access: January 2019).
Wang, L. and Robertson, A. W.: Week 3-4 predictability over the United States assessed from two operational ensemble prediction systems, Clim. Dynam., 52, 5861-5875, 2019.

Wernli, B. H. and Davies, H. C.: A Lagrangian-based analysis of extratropical cyclones. I: The method and some applications, Q. J. Roy. Meteor. Soc., 123, 467-489, 1997.

Wernli, H. and Bourqui, M.: A Lagrangian "1-year climatology" of (deep) cross-tropopause exchange in the extratropical Northern Hemisphere, J. Geophys. Res., 107, ACL 13-1-ACL 13-16, https://doi.org/10.1029/2001JD000812, 2002.

Wernli, H. and Sprenger, M.: Identification and ERA-15 climatology of potential vorticity streamers and cutoffs near the extratropical tropopause, J. Atmos. Sci., 64, 1569-1586, 2007.

Yamagami, A. and Matsueda, M.: Subseasonal Forecast Skill for Weekly Mean Atmospheric Variability Over the Northern Hemisphere in Winter and Its Relationship to Midlatitude Teleconnections, Geophys. Res. Lett., 47, e2020GL088508, https://doi.org/10.1029/2020GL088508, 2020.

Younas, W. and Tang, Y.: PNA predictability at various time scales, J. Climate, 26, 9090-9114, 2013.

Young, P. J., Naik, V., Fiore, A. M., Gaudel, A., Guo, J., Lin, M. Y., Neu, J. L., Parrish, D. D., Rieder, H. E., Schnell, J. L., Tilmes, S., Wild, O., Zhang, L., Ziemke, J., Brandt, J., Delcloo, A., Doherty, R. M., Geels, C., Hegglin, M. I., Hu, L., Im, U., Kumar, R., Luhar, A., Murray, L., Plummer, D., Rodriguez, J., Saiz-Lopez, A., Schultz, M. G., Woodhouse, M. T., and Zeng, G.: Tropospheric Ozone Assessment Report: Assessment of global-scale model performance for global and regional ozone distributions, variability, and trends, Elementa: Science of the Anthropocene, 6, 10, https://doi.org/10.1525/elementa.265, 2018.

Zhu, Y. and Newell, R. E.: A proposed algorithm for moisture fluxes from atmospheric rivers, Mon. Weather Rev., 126, 725$735,1998$. 